\title{
The Carbon Cycle Response to ENSO: A Coupled Climate-Carbon Cycle Model Study
}

\author{
Chris D. Jones, Matthew Collins, Peter M. Cox, and Steven A. Spall \\ Hadley Centre, Met Office, Bracknell, Berkshire, United Kingdom
}

(Manuscript received 30 October 2000, in final form 24 April 2001)

\begin{abstract}
There is significant interannual variability in the atmospheric concentration of carbon dioxide $\left(\mathrm{CO}_{2}\right)$ even when the effect of anthropogenic sources has been accounted for. This variability is well correlated with the El Niño-Southern Oscillation (ENSO) cycle. This behavior of the natural carbon cycle provides a valuable mechanism for validating carbon cycle models. The model in turn is a valuable tool for examining the processes involved in the relationship between ENSO and the carbon cycle.

A GCM coupled climate-carbon cycle model is used to study the mechanisms involved. The model simulates the observed temperature, precipitation, and $\mathrm{CO}_{2}$ response of the climate to the ENSO cycle. Climatic changes over land during El Niño events lead to decreased gross primary productivity and increased plant and soil respiration, and hence the terrestrial biosphere becomes a source of $\mathrm{CO}_{2}$ to the atmosphere. Conversely, during El Niño events, the ocean becomes a sink of $\mathrm{CO}_{2}$ because of reduction of equatorial Pacific outgassing as a result of decreased upwelling of carbon-rich deep water. During La Niña events the opposite occurs; the land becomes a sink and the ocean a source of $\mathrm{CO}_{2}$.

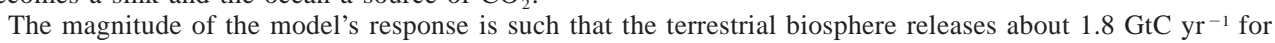
an El Niño with a Niño-3 index of magnitude $1{ }^{\circ} \mathrm{C}$, and the oceans take up about $0.5 \mathrm{GtC} \mathrm{yr}^{-1}$. $\left(1 \mathrm{GtC}=10^{15}\right.$ $\mathrm{g}$ of carbon). The net global response is thus an increase in atmospheric $\mathrm{CO}_{2}$ of about $0.6 \mathrm{ppmv} \mathrm{yr}^{-1}$. This is in close agreement with the sensitivity of the observed $\mathrm{CO}_{2}$ record to ENSO events.
\end{abstract}

\section{Introduction}

Records of atmospheric carbon dioxide $\left(\mathrm{CO}_{2}\right)$ concentration have been kept for Mauna Loa, Hawaii, and the South Pole since 1958 and are described in detail in Keeling et al. (1989). These records show a clear seasonal cycle with a long-term upward trend attributed to the burning of fossil fuel. However, once the longterm trend and the seasonal cycle have been removed (Keeling et al. 1989), the data shows interannual variability that cannot be readily explained by changes in fossil fuel burning.

The correlation between these anomalous changes in atmospheric $\mathrm{CO}_{2}$ and the El Niño-Southern Oscillation (ENSO) cycle was first reported in the 1970s (Bacastow 1976; Bacastow et al. 1980). It was noticed that during El Niño events, atmospheric $\mathrm{CO}_{2}$ concentrations increased at four monitoring stations (Mauna Loa $19^{\circ} \mathrm{N}$, South Pole $90^{\circ} \mathrm{S}$, Fanning Island $4^{\circ} \mathrm{N}$, Ocean Station P $50^{\circ} \mathrm{N}$ ), and was thus assumed to be a signal of global extent. Conversely, during La Niña events, atmospheric $\mathrm{CO}_{2}$ was reduced at each station. The magnitude of the response to ENSO was found to be $\pm 0.5-1 \mathrm{ppmv}$.

Corresponding author address: Chris D. Jones, Hadley Centre, Met Office, London Road, Bracknell, Berkshire RG12 2SY, United Kingdom.

E-mail: chris.d.jones@metoffice.com
In this study we use observational data of atmospheric $\mathrm{CO}_{2}$ concentration and the ENSO cycle to validate a coupled climate-carbon cycle, ocean-atmosphere general circulation model (GCM). The comparison of model and data gives us confidence that the model is capturing the important responses of the carbon cycle to ENSO. We subsequently use the model to examine the behavior of the terrestrial biosphere and the ocean carbon cycle in more detail and to try to explain the mechanisms linking ENSO and the response of the carbon cycle. Similar studies of the ocean or terrestrial carbon cycle have been performed before, but the ability of our model to include both as interactive elements of a GCM, allows them to be compared within a consistent framework.

Another motivation for studying the impact of the ENSO cycle on the carbon cycle is that several studies have found that the pattern of anthropogenic climate change over the next century in some GCM simulations resembles an El Niño-like warming pattern (Roeckner et al. 1999; Meehl et al. 2000; Boer et al. 2000). Hence an understanding of how the carbon cycle responds to ENSO forcing may provide valuable insight into how it may respond to future climate change.

The observational record is described further in section 2 along with a discussion of published theories regarding the mechanisms linking ENSO and the carbon cycle. In section 3 the model configuration is described 
along with the model's simulation of El Niño events. Sections 4 and 5 look closer at the terrestrial and ocean components of the model's carbon cycle to see how each responds to ENSO forcing. Our conclusions are summarized in section 6 .

\section{Observed signal}

To determine natural carbon cycle variability it is first necessary to remove the major man-made influence from the record, namely anthropogenic $\mathrm{CO}_{2}$ emissions. Annual anthropogenic emissions are of the order of $1 \%$ of the total atmospheric store of $\mathrm{CO}_{2}$ and so have a significant cumulative effect on the concentration of $\mathrm{CO}_{2}$ in the atmosphere. Keeling et al. (1995) show that from 1959 to 1979 , a nearly constant fraction (56\%) of these emissions remained in the atmosphere with the remainder being absorbed by the oceans and terrestrial biosphere.

The observed record of atmospheric $\mathrm{CO}_{2}$ concentration is available from the Carbon Dioxide Information Analysis Center (CDIAC, available online at http:// cdiac.esd.ornl.gov/, dataset number NDP001). Annual mean concentrations from the Mauna Loa observatory in Hawaii are available from 1958 up to 1998 , but due to missing data in 1964 we only consider the record from 1965 to 1998. Gammon et al. (1985) show that Mauna Loa $\mathrm{CO}_{2}$ concentration can be used as a proxy for global mean concentration, including a correction by a constant $0.2 \mathrm{ppm}$. Hence from the Mauna Loa record we infer annual mean changes in global mean atmospheric $\mathrm{CO}_{2}$.

Anthropogenic emissions are also available online from the CDIAC Website (dataset number NDP030). Using the assumption that $56 \%$ of these emissions remains airborne (Keeling et al. 1995) we calculate interannual changes of atmospheric $\mathrm{CO}_{2}$ due to the emissions. This contribution is then subtracted from the previous calculated annual mean changes to leave the "natural" component of atmospheric $\mathrm{CO}_{2}$ changes. Note that the emissions data obtained from CDIAC only goes up to 1996 , so for the years 1997-99 the anthropogenic contribution to atmospheric $\mathrm{CO}_{2}$ changes is taken from the IS92a scenario (available online at the CDIAC Web site, dataset number DB1009). Other methods of removing the anthropogenic signal were also tried, such as spline fitting (Enting 1987), locally weighted regression (Cleveland et al. 1983), or simply subtracting a linear trend from the data. The results obtained were very similar to our chosen method of subtracting $56 \%$ of emissions, and the results discussed below were robust to the choice of processing.

The interannual variability in atmospheric $\mathrm{CO}_{2}$, which remains (the "natural $\Delta \mathrm{CO}_{2}$ "), is highly correlated with the ENSO cycle. The measure of El Niño used here is the Niño-3 index: the mean SST anomaly in the region $5^{\circ} \mathrm{N}-5^{\circ} \mathrm{S}, 150^{\circ}-90^{\circ} \mathrm{W}$ that is derived from the climatological SST dataset, "HadISST1.1" (Rayner

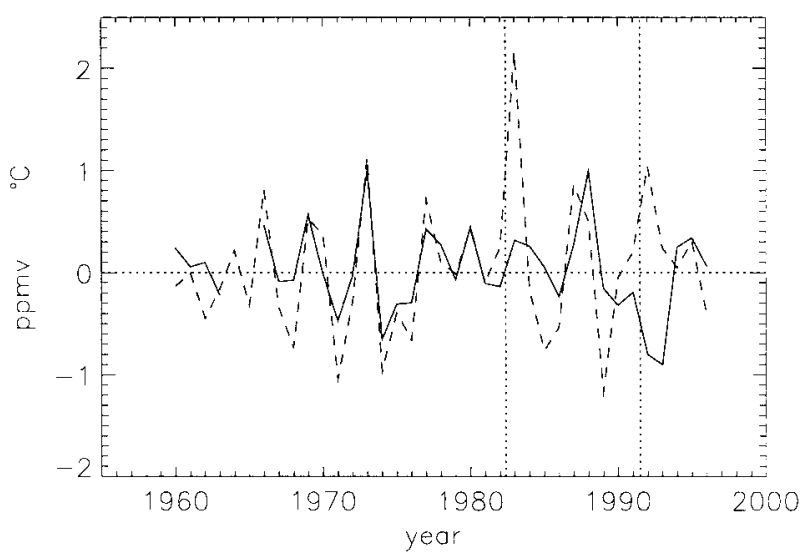

FIG. 1. Time series of the observed Niño-3 index $\left({ }^{\circ} \mathrm{C}\right)$ (dashed line) and the natural changes in atmospheric $\mathrm{CO}_{2}$ (ppmv) (solid line). (scale for both quantities is the same). The eruptions of El Chichón and Mount Pinatubo are indicated by the vertical dotted lines.

et al. 2000). A positive Niño-3 index indicates an El Niño event, and a negative one indicates a La Niña event. Figure 1 shows the time series of the historical Niño-3 index and the natural changes in atmospheric $\mathrm{CO}_{2}$. The correlation of increased $\mathrm{CO}_{2}$ during El Niño events is clear. The correlation coefficient for annual means from 1966 to 1996 is 0.44 , which is significant at the $95 \%$ level. Correlations with 1-yr lag of $\mathrm{CO}_{2}$ changes showed significantly lower values. There are periods when the relationship does not hold, namely, 1982-84 and 1991-93. These periods coincide with times when the troposphere was cooled by the impact of volcanic eruptions (El Chichón, Mexico, in 1982 and Mount Pinatubo, the Phillipines, in 1991, shown by vertical dotted lines in Fig. 1) and may have lead to decreased respiration from plants and soil, causing a net uptake by the terrestrial biosphere. The impact of a major volcanic eruption on the natural carbon cycle is described in more detail in Jones and Cox (2001).

The reasons for the correlation of carbon cycle variability and ENSO have received a lot of attention in the literature in recent years. As pointed out by Nakazawa et al. (1997) it is important to understand the natural carbon cycle before we can have confidence in our predictions of future levels of $\mathrm{CO}_{2}$, and the associated climate change.

When the correlation between interannual changes in $\mathrm{CO}_{2}$ and ENSO was first noticed it was thought that the reason lay in the ocean's behavior, with a net outgassing of $\mathrm{CO}_{2}$ from the ocean during El Niño events, and a net uptake under La Niña conditions. Bacastow (1976) postulated that increased winds, especially in the Southern Ocean, during La Niña events could lead to higher gas exchange between the atmosphere and ocean and hence oceanic uptake. Bacastow et al. (1980) suggested that increased upwelling of nutrients in the equatorial Pacific during La Niña years could increase biological activity and hence increase uptake, and also that in- 
creased SSTs during El Niña years would serve to increase outgassing during these periods by reducing the solubility of $\mathrm{CO}_{2}$. However, Feely (1987) argued that the most important El Niño impact on the equatorial Pacific is by reduced upwelling of dissolved inorganic carbon (DIC), which lowers the partial pressure of $\mathrm{CO}_{2}$ dissolved in surface water $\left(\mathrm{pCO}_{2}\right)$, and hence reduces the outgassing during El Niño years, leading to a net uptake of $\mathrm{CO}_{2}$ by the world's oceans. Feely (1987) also suggest that under El Niño conditions reduced winds in the equatorial Pacific result in reduced outgassing.

Winguth et al. (1994) used an ocean modeling approach to estimate that the ocean had a net uptake of

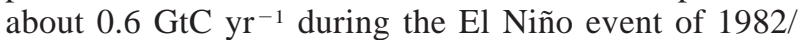
$83\left(1 \mathrm{GtC}=10^{15} \mathrm{~g}\right.$ of carbon). They concluded therefore that the terrestrial biosphere must have been a source

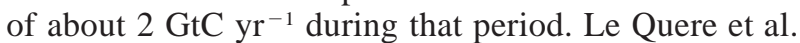
(2000) also found strong correlation between air-sea fluxes and ENSO, with anomalous ocean uptake during El Niños and anomalous release during La Niñas. Their results were dominated by the behavior in the equatorial Pacific. More recently it has become established that the ocean and terrestrial carbon cycles respond in opposite senses to ENSO forcing. Keeling et al. (1995) and Francey et al. (1995) both describe how El Niño events cause the oceans to become a net sink for $\mathrm{CO}_{2}$ due to decreased upwelling of DIC in the equatorial Pacific, and the terrestrial biosphere to become a net source, possibly due to increased respiration or increased incidence of natural fires and biomass burning.

Using inverse tracer transport models and isotopic data such as $\delta^{13} \mathrm{C}$ measurements, several studies have been able to try to recreate patterns of $\mathrm{CO}_{2}$ sources and sinks and estimate regional contributions to global totals. Ciais et al. (1995) identify a net sink of $3.1 \mathrm{GtC}$ $\mathrm{yr}^{-1}$ into the world's oceans, and $1.5 \mathrm{GtC} \mathrm{yr}^{-1}$ into the terrestrial biosphere during 1992/93. However, it is possible that this period was anomalous as it was then that tropospheric cooling following the eruption of Pinatubo in 1991 was at its peak. Nakazawa et al. (1997) use the fact that $\delta^{13} \mathrm{C}$ observations decrease in El Niño years while $\mathrm{CO}_{2}$ concentrations increase to argue that the dominant response must come from the terrestrial biosphere rather than the oceans, and Bousquet et al. (2000) deduce that the tropical biomes are responsible for the majority of this ENSO-driven variability. However Rayner and Law (1999) point out that however successful inversion studies are for identifying or locating sources and sinks of $\mathrm{CO}_{2}$, they cannot be used to explain the behavior. For this, process-based models are required.

Various studies have attempted to explain the oceanic and terrestrial response to the ENSO cycle. In the case of the ocean at least, a fair degree of consensus has been reached. Most studies (e.g., Feely 1987; Winguth et al. 1994; Francey et al. 1995) agree that the dominant cause of oceanic net uptake in El Niño years is reduced upwelling of DIC in the equatorial Pacific resulting in reduced outgassing there (this region is the largest nat- ural source of $\mathrm{CO}_{2}$ to the atmosphere in the world). However other effects may also be important:

- Bacastow et al. (1980) suggest that increased SSTs in this region will reduce the solubility of $\mathrm{CO}_{2}$ and enhance the outgassing. However Wong et al. (1993) claim that this will be countered by the influence of temperature on air-sea gas exchange: increased temperatures decrease the transfer velocity and so reduce the fluxes.

- Several studies (e.g., Wong et al. 1993; Feely 1987) have found that reduced equatorial Pacific winds during El Niño events play a part in reducing the outgassing of $\mathrm{CO}_{2}$ in that region.

- Wong et al. (1993) find that the peak of nutrient observed in the equatorial Pacific in non-El Niño years is not found in El Niño years, implying that the reduced upwelling of nutrient may cause biological activity in this region to be nutrient limited in El Niño years. However Archer et al. (1996) find that biological changes are not responsible for changing surface $\mathrm{pCO}_{2}$ values in the equatorial Pacific: these can be explained solely by the changes in upwelled DIC.

- Karl et al. (1995) find that primary production in the northern Pacific subtropical gyre does increase (by $65 \%$ in El Niño years, although it is not known what effect this has on oceanic $\mathrm{CO}_{2}$ uptake.

There is general agreement that the terrestrial biosphere is a net source of $\mathrm{CO}_{2}$ to the atmosphere in El Niño years (e.g., Francey et al. 1995; Keeling et al. 1995). Also, Myneni et al. (1998) see a response in the normalized difference vegetation index power spectrum at the same frequency as the ENSO cycle. However, the mechanisms behind this response are less well understood. The reason for this may be that any response of the terrestrial carbon cycle to El Niño events will be a result of changing atmospheric conditions induced by the El Niño, whereas in the case of the ocean the main impact on the carbon cycle is driven directly by the same mechanism that causes the anomalous SSTs: namely the reduced upwelling of colder, carbon-rich deep water. Understanding the link between El Niño events and global weather patterns, and then the effect of these on the terrestrial biosphere is more complex.

Nicholls (1991) describes how levels of precipitation in Australia are well correlated with ENSO activity: El Niño events are often accompanied by drought and La Niña events by flooding. Such changes in precipitation affect the growth of vegetation in Australia with aboveaverage growth, and therefore uptake of atmospheric $\mathrm{CO}_{2}$, in the wet periods associated with La Niña conditions. Nicholls (1991) also suggests that increased winds during the warmer, drier El Niño periods increase the incidence of natural fires, causing a net source of $\mathrm{CO}_{2}$ to the atmosphere. Keeling et al. (1995) also suggest that increased fire activity during El Niño periods contributes to a net outgassing from the terrestrial biosphere, and Liew et al. (1998) estimate the $\mathrm{CO}_{2}$ emis- 
sions from the Southeast Asian fires in Sumatra and Borneo in 1997 that were aggravated by the El Niñoinduced drought there. However, there is no clear agreement on whether changing growth and respiration rates of vegetation are driven by temperature or precipitation changes. Craig (1998) used a modeling study to conclude that changing precipitation patterns were the dominant cause, in particular the changes seen in monsoon conditions during El Niño years. However, Kindermann et al. (1996) and Gerard et al. (1999) found that when they forced their models with both temperature and precipitation changes and with temperature changes alone, then temperature changes alone were sufficient to produce the observed changes in terrestrial carbon uptake and release. To further complicate the picture, Gerard et al. (1999) noted that different vegetation types could produce a similar net response to changing conditions through different mechanisms: savannah-type vegetation regions tended to see larger changes in Gross Primary Productivity (GPP) and only small changes to respiration rates, whereas tropical forests that were not water stressed experienced larger changes in respiration rates and smaller changes in GPP.

\section{Model description and validation}

\section{a. Model setup}

The model used here ("HadCM3LC") is a coupled ocean-atmosphere GCM with an interactive carbon cycle representing both terrestrial and oceanic carbon cycles. The GCM is a version of the third Hadley Centre coupled ocean-atmosphere model, HadCM3 (Gordon et al. 2000), but with a lower ocean resolution of $2.5^{\circ} \times$ $3.75^{\circ}$ and the use of flux adjustments. The carbon cycle component comprises an ocean carbon cycle model and a dynamic global vegetation model.

The Hadley Centre's Ocean Carbon Cycle model ("HadOCC") accounts for the atmosphere-ocean surface exchange of $\mathrm{CO}_{2}$, and the transfer of $\mathrm{CO}_{2}$ to depth through both the solubility pump (Taylor 1995) and the biological pump. The inorganic component has been extensively tested as part of the Ocean Carbon Cycle Intercomparison Project, by which it was found to reproduce tracer distributions to an accuracy consistent with other ocean GCMs (Orr 1996). The biological component treats four additional ocean fields: nutrient, phytoplankton, zooplankton, and detritus (Palmer and Totterdell 2001).

The terrestrial carbon cycle model, "TRIFFID" (Cox 2001), simulates the state of the terrestrial biosphere in terms of the soil carbon, and the structure and coverage of five plant functional types within each model gridbox (broadleaf tree, needleleaf tree, $\mathrm{C}_{3}$ grass, $\mathrm{C}_{4}$ grass, and shrub). Carbon fluxes for each type are calculated every $30 \mathrm{~min}$ as a function of climate and atmospheric $\mathrm{CO}_{2}$ concentration, from a coupled photosynthesis-stomatal conductance scheme (Cox et al. 1998, 1999), which utilizes existing models of leaf-level photosynthesis in $\mathrm{C}_{3}$ and $\mathrm{C}_{4}$ plants (Collatz et al. 1991, 1992). Plant respiration is broken down into a growth component that is proportional to the photosynthetic rate and a maintenance component that is assumed to increase exponentially with temperature $\left(q_{10_{v}}=2.0\right)$. The accumulated fluxes are used to update the vegetation and soil carbon every 10 days. The natural land cover evolves dynamically based on competition between the types, which is modeled using a Lotka-Volterra approach (Huntingford et al. 2000) and a (tree-shrub-grass) dominance hierarchy. Agricultural regions are prescribed, in which grasslands are assumed to be dominant. Carbon lost from the vegetation as a result of local litterfall or largescale disturbance, is transferred into a soil carbon pool, where it is broken down by microorganisms that return $\mathrm{CO}_{2}$ to the atmosphere. The soil respiration rate is dependent on the soil moisture content in the manner suggested by McGuire et al. (1992), and is assumed to double for every $10 \mathrm{~K}$ of warming (i.e., $q_{10_{s}}=2.0$ ), which represents a central estimate of the temperature sensitivity based on observations (Raich and Schlesinger 1992). The long-term response of TRIFFID to $\mathrm{CO}_{2}-$ induced climate change has been analyzed as part of an offline comparison of dynamic global vegetation models (Cramer et al. 2001).

In this paper we focus on shorter-term variability in the carbon cycle as simulated "online" within the GCM. HadCM3LC was brought to equilibrium with a "preindustrial" atmospheric $\mathrm{CO}_{2}$ concentration of 290 ppmv, starting from an observed land cover dataset (Wilson and Henderson-Sellers 1985). From the resulting state, a long control run of the model was performed, which was stable, with negligible net land-atmosphere and ocean-atmosphere carbon fluxes in the long-term mean, and no discernible drift in atmospheric $\mathrm{CO}_{2}$. This simulation produces the locations of the major land biomes, and estimates of the major carbon pools and fluxes. The control experiment and results are described in detail in Cox et al. $(2000,2001)$.

\section{b. El Niño-Southern Oscillation}

It was described above how the natural carbon cycle is strongly modulated by ENSO and hence any model simulation of this modulation is limited by the model's ability to simulate the ENSO phenomenon. ENSO is an inherently coupled mode of variability and models with coarse ocean resolution (of the order of that used in HadCM3LC) often simulate an ENSO that is either too weak (e.g., Meehl et al. 1993; Knutson et al. 1997) or that has a pattern of variability that is shifted to the central Pacific from its observed eastern Pacific position (e.g., Collins 2000). Models with higher ocean resolution (e.g., Timmermann et al. 1999; Collins et al. 2001) are beginning to have more realistic ENSO simulations, although there are still improvements to be made.

Figure 2 shows the interannual standard deviation of 


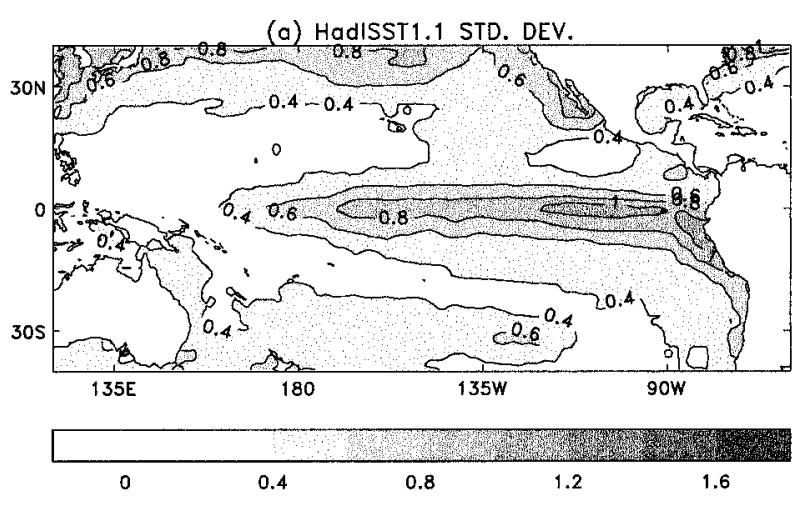

(b) HadCM3LC SST STD. DEV.

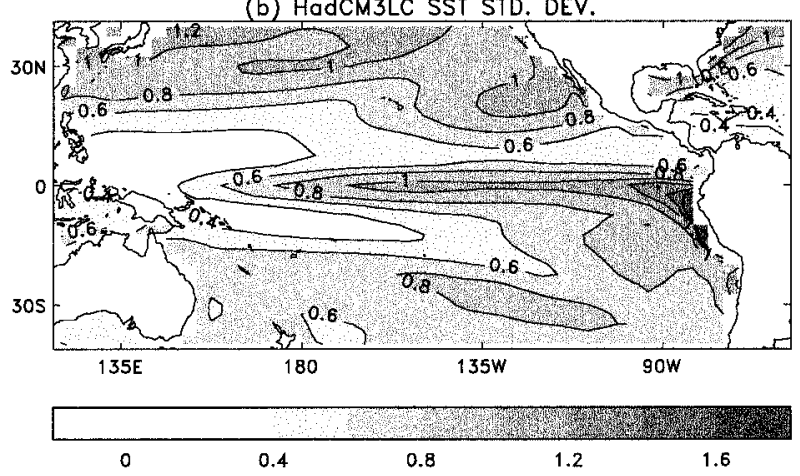

FIG. 2. The std dev of interannual SST anomalies in the tropical Pacific region for (a) the HadISST1.1 observed SSTs and (b) $300 \mathrm{yr}$ of the HadCM3LC simulation. The contour interval is $0.2 \mathrm{~K}$.

SST in the tropical Pacific for the observations (HadISST1.1; Rayner et al. 2000) and for HadCM3LC. As is the case for other coupled models with similar ocean resolution, HadCM3LC has a region of variability that is similar to the observations, but that extends slightly too far into the central to west Pacific —although this misplacement of the variability is not as pronounced as that seen, for example, in HadCM2 (Collins 2000; Fig. 2). Also, the model simulates more realistic variability in the eastern Pacific along the coast of South America that was not simulated in HadCM2. The amplitude of the SST variability is similar to that observed, being slightly larger than seen in the HadISST data. The method used to construct the HadISST observations smoothes the raw data somewhat and hence the observed SST standard deviation may be a slight underestimation of the real standard deviation (Rayner et al. 2000). Hence the model simulates the ocean component of ENSO with an amplitude than is similar to that observed.

ENSO has a well-known timescale of 2-8 yr that can be characterized by a broad peak in the spectra at these periods. We use the Niño-3 index for ENSO and compute the power spectra by taking the Fourier transform of the autocovariance function of the time series and then applying a Tukey-Hanning window of width $14 \mathrm{yr}$ (e.g., Chatfield 1984). HadCM3LC has a broad peak in

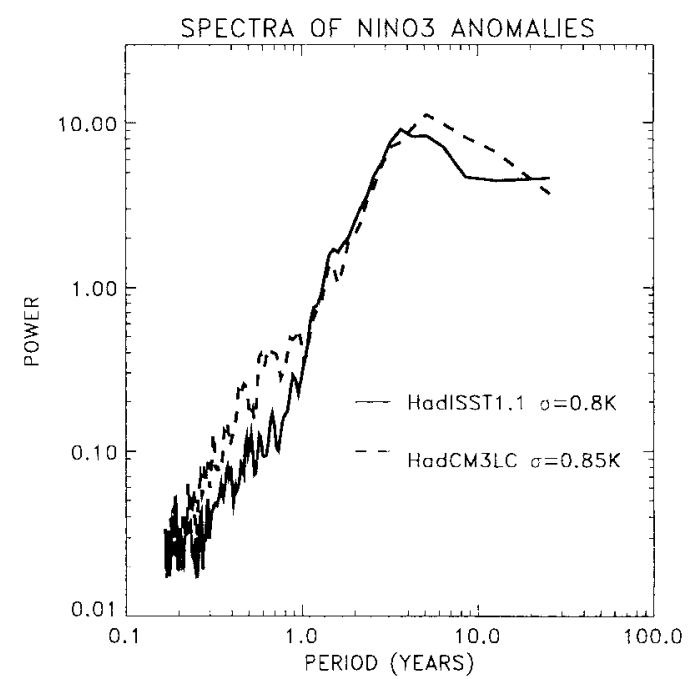

FIG. 3. Estimated power spectra of Niño-3 SST anomalies for the HadISST1.1 observations (solid line) and for the HadCM3LC simulation (dashed line). Power spectra were smoothed using a TukeyHanning window of width $14 \mathrm{yr}$.

the spectra at periods of $2-8 \mathrm{yr}$ similar to that seen in the power spectra of the observed Niño-3 index (Fig. 3 ), with a peak at a slightly longer period than observed and rather more power at subannual timescales that is seen in the observations. Thus the model ENSO has a timescale that is similar to that observed.

To study the teleconnection patterns we follow Tett et al. (1997) and perform a regression analysis between the annually averaged surface temperatures and the temperature anomalies averaged in the Niño-3 region. The regression coefficients $(\beta)$ are shown in Fig. 4 for the observations (UEA-MOHHST temperature dataset; Parker et al. 1995) and HadCM3LC. In the observations, there are large regression coefficients in the tropical regions over the Pacific, over the Indian Ocean, and to a lesser extent over the tropical Atlantic. There are also positive coefficients to the north and south of the tropical Pacific showing the main midlatitude response to ENSO. The regression coefficients of HadCM3LC are broadly similar to those of the observations, showing the same key features. HadCM3LC has teleconnections that are slightly too strong in the western tropical $\mathrm{Pa}$ cific, and much too strong over Africa and the Indian Ocean.

Another well-known feature of ENSO is the tendency for the oscillation to reach its maximum or minimum during Northern Hemisphere winter. The Niño-3 time series shown in Fig. 5 highlights this tendency for both the model and the observations, although this "phase locking" is perhaps not so obvious for the model series. The enhanced subannual timescale variability in comparison with the observations (Fig. 4) complicates the diagnosis of the phase locking; however, it appears that for the major ENSO events in the model the maximum 
(a) UEA-MOHSST REGRESSION ON HodISST1.1 NINO3: $\beta$

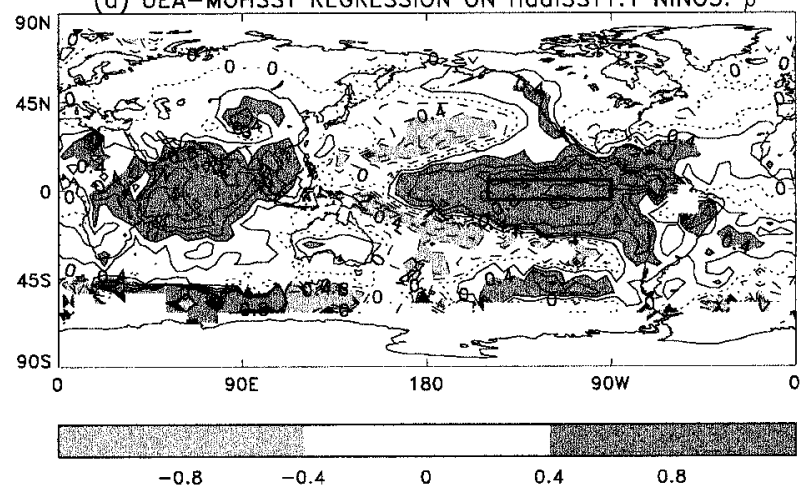

(b) HOdCM3LC REGRESSION ON NINO3: $\beta$

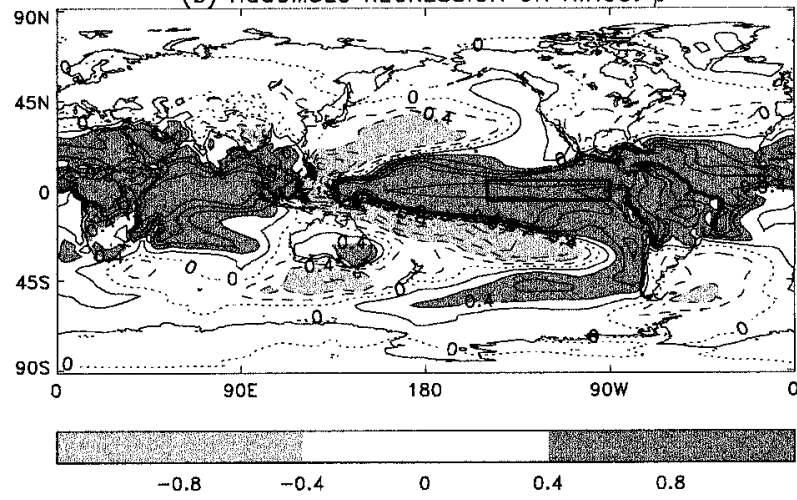

FIG. 4. Regression coefficients of (a) annual averaged surface air temperature from the UEA-MOHSST dataset regressed against HadISST1.1 Niño-3 anomalies and (b) annual averaged HadCM3LC $1.5-\mathrm{m}$ air temperature regressed against Niño-3 SST anomalies. The contour interval is 0.2 and values less than -0.4 are indicated by the light shading and values greater than 0.4 are indicated by the dark shading. (Rectangular box in both panels shows area covered by the Niño-3 index region).

amplitude of Niño-3 anomaly occurs during northern winter.

\section{c. Temperature and precipitation response to ENSO}

It was mentioned earlier that the response of the terrestrial carbon cycle to ENSO forcing must be through the response of the atmospheric climate, in particular, temperature and precipitation. Here we compare the response of the model's temperature and precipitation over land to ENSO forcing with the response of observed temperature and precipitation.

Figures $6 a, c$ show the regression of observed temperature onto the observed Niño-3 index, and the regression of the model's $1.5-\mathrm{m}$ air temperature onto the model's Niño-3 index. The data have been masked to land points. The model's temperature response over land is in broad agreement with the observations, although the regression coefficients tend to be higher for the model than the observations. There is a positive correlation between Niño-3 index and temperature throughout trop- ical land in both model and observations. The model recreates the dipole of positive correlation in northwest North America, and negative correlation in the southeast and also the positive correlation over Australia. The model however is not so good in northern Asia, where it has a positive correlation in Siberia compared with a negative correlation in the observations. There is also a patch of positive correlation in the observations in central Asia that the model does not capture.

For precipitation we use the Climatic Research Unit (CRU) precipitation data of Hulme (1994). It should be noted that some regions have only sparse data coverage, which means that the data that is available may not be representative of regional averages (Myneni et al. (1996)). The regression coefficients of observed precipitation onto observed Niño-3 index and modeled precipitation onto modeled Niño-3 index are shown in Figs. $6 \mathrm{~b}$,d. The model data have been masked to the same points as the observations. The model is again in broad agreement with the observations. It captures the negative correlation in northern South America and positive correlation in the south, and it recreates the negative correlations in Australia and India and the positive correlations in the United States and Eurasia. The main disagreement however is in North Africa where the observations show a negative correlation and the model a positive one. This error in the model precipitation response to ENSO is however of little consequence for the results of this paper as North Africa does not play a significant role in the carbon cycle's response to ENSO (see Figs. 9 and 6).

The response to ENSO of the temperature and precipitation fields over land is generally well captured by the model. There are some regions where the modeled response is at odds with observations. These differences are likely a result of limitations of the model, but limited numbers of observations may also be a factor. These areas where model and data disagree are discussed when the response of the terrestrial ecosystem to the ENSO forcing is examined in depth in section 4.

\section{d. Carbon cycle response to ENSO}

\section{1) Global atmospheric $\mathrm{CO}_{2}$ CONCENTRAtion}

The model's net $\mathrm{CO}_{2}$ flux can be compared with observed changes in $\mathrm{CO}_{2}$ concentration (observed largescale fluxes themselves are not available). Figure 7 shows observed changes in annual mean $\mathrm{CO}_{2}$ concentration after the anthropogenic influence has been removed (as described in section 2) plotted against observed Niño-3 index from the HadISST dataset.

The period from 1967 to 1981 inclusive is free from any volcanic influence, and the two data series show a very good correlation during this period (correlation coefficient is 0.92; significant at the $99 \%$ level). A linear regression has been performed to calculate a line of best fit to the data from this period (solid line in Fig. 7). The 
(a) HadISST1.1 NINO3

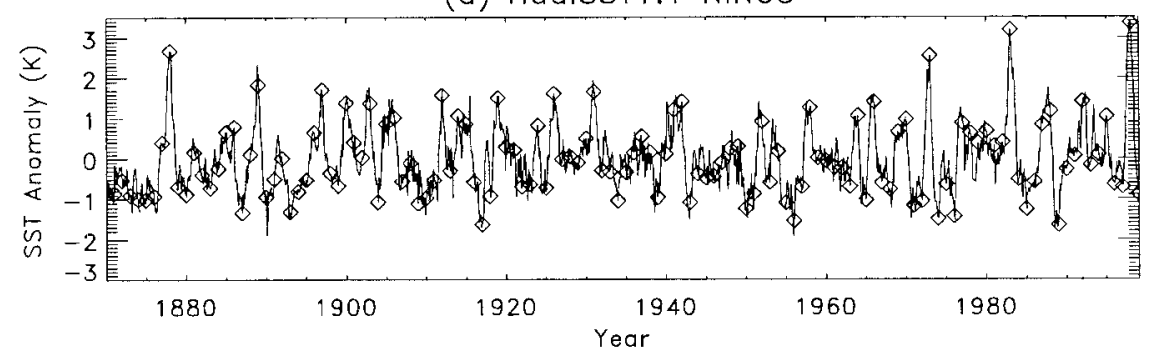

(b) HadCM3LC NINO3

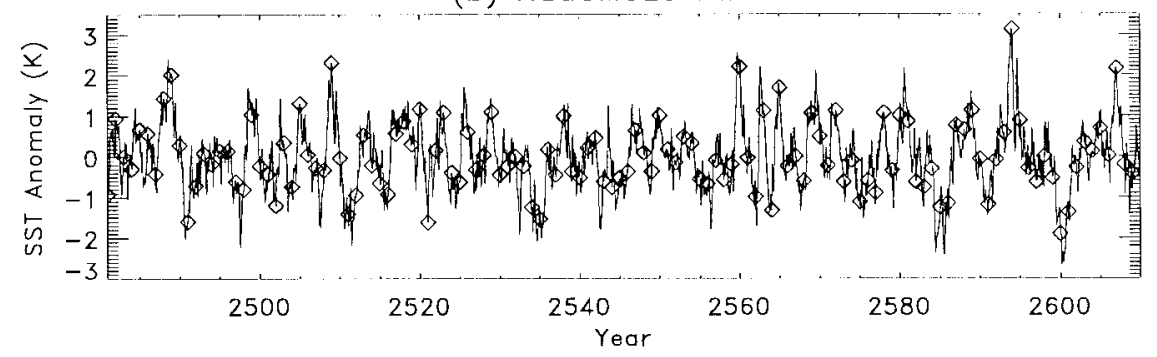

FIG. 5. Time series of interannual Niño-3 SST anomalies (monthly means with the annual cycle removed) for (a) the HadISST1.1 observations and (b) the HadCM3LC simulation. The diamonds show the Dec mean values of Niño-3 indicating the phase locking of ENSO to the annual cycle, i.e., ENSO peaks during northern winter.

slope of the line is $0.63 \pm 0.16 \mathrm{ppm} \mathrm{yr}^{-1}{ }^{\circ} \mathrm{C}^{-1}$, that is, atmospheric $\mathrm{CO}_{2}$ rises by $0.63 \mathrm{ppm} \mathrm{yr}^{-1}$ for each degree of positive temperature anomaly in the Niño-3 region. The error is calculated as the $95 \%$ confidence interval of the regression and is shown in the figure as dotted lines.

Data from years following a major volcanic eruption are likely to be contaminated by the signal of the volcanic cooling (Jones and Cox 2001). The regression calculation was repeated for data from the entire period except the years 1983, 1992, 1993 (which were strongly affected by the eruptions of El Chichón in 1982 and Mount Pinatubo in 1991; these points are plotted as open triangles in Fig. 7). The effect of the volcanic influence is to reduce the slope slightly; the slope calculated for this period (not shown) is $0.51 \pm 0.16 \mathrm{ppm} \mathrm{yr}^{-1}{ }^{\circ} \mathrm{C}^{-1}$.

Figure 8a shows an equivalent plot to Fig. 7 , for the model run. The pattern is very similar to the observed pattern (again the correlation is significant at the 99\% level), and the slope of the best-fit line is $0.60 \pm 0.1$ $\mathrm{ppm} \mathrm{yr}^{-1}{ }^{\circ} \mathrm{C}^{-1}$. This is very close to the value calculated from the observations, showing that the model's carbon cycle has about the right level of sensitivity to ENSO forcing. As noted earlier, the model's ENSO has slightly too high a magnitude. This is evident again in Fig. 8, where values of Niño-3 index above $1.0^{\circ} \mathrm{C}$ are more common than in the observations. Therefore, even though the model's carbon cycle has realistic sensitivity to ENSO, the variability in the carbon fluxes will be of a slightly greater magnitude than observed.

Figure 9 shows the distribution of anomalous fluxes for mean El Niño conditions and La Niña conditions.
The mean flux from the ocean during El Niño years is negative, with the main area of anomalous flux being the net uptake (relative to the long-term mean) of the equatorial Pacific. Over land, the terrestrial biosphere becomes a net source of $\mathrm{CO}_{2}$ to the atmosphere during El Niño years. The largest response is seen in the Tropics, in particular in South America. The reverse is true in La Niña years. This behavior of the terrestrial and ocean carbon cycles responding in opposite senses to ENSO forcing is in agreement with the findings of Keeling et al. (1995) and Francey et al. (1995). Figures 8b,c show scatterplots of the ocean and terrestrial carbon fluxes respectively against the Niño-3 index. The difference in their behavior is clear. The lines of best fit show that for each degree of positive temperature anomaly in the Niño-3 region, the ocean absorbs $0.49 \pm 0.04$ $\mathrm{GtC} \mathrm{yr}^{-1}$ and the terrestrial biosphere releases $1.76 \pm$

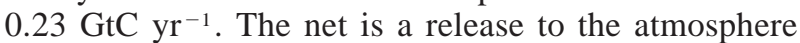
of $1.27 \mathrm{GtC} \mathrm{yr}^{-1}$, or an increase of $0.60 \mathrm{ppm} \mathrm{yr}^{-1}$. These values are larger than that calculated by Winguth et al. (1994) of $0.6 \mathrm{GtC}$ uptake by the ocean and $2 \mathrm{GtC}$ released by the land for the 1982/83 El Niño that had a Niño-3 index of about $2^{\circ} \mathrm{C}$. However these observations coincide with the eruption of El Chichón in 1982 that cooled the troposphere and may have produced a reduction in the impact of the El Niño on the carbon fluxes (Jones and Cox 2001).

The sensitivity of the ocean $\left(0.49 \pm 0.04 \mathrm{GtC} \mathrm{yr}^{-1}\right.$ ${ }^{\circ} \mathrm{C}^{-1}$ ) compares well with Le Quere et al. (2000) who forced an ocean GCM with observed atmospheric con-

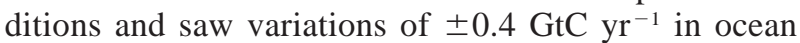
fluxes during a period where the annual mean variations 

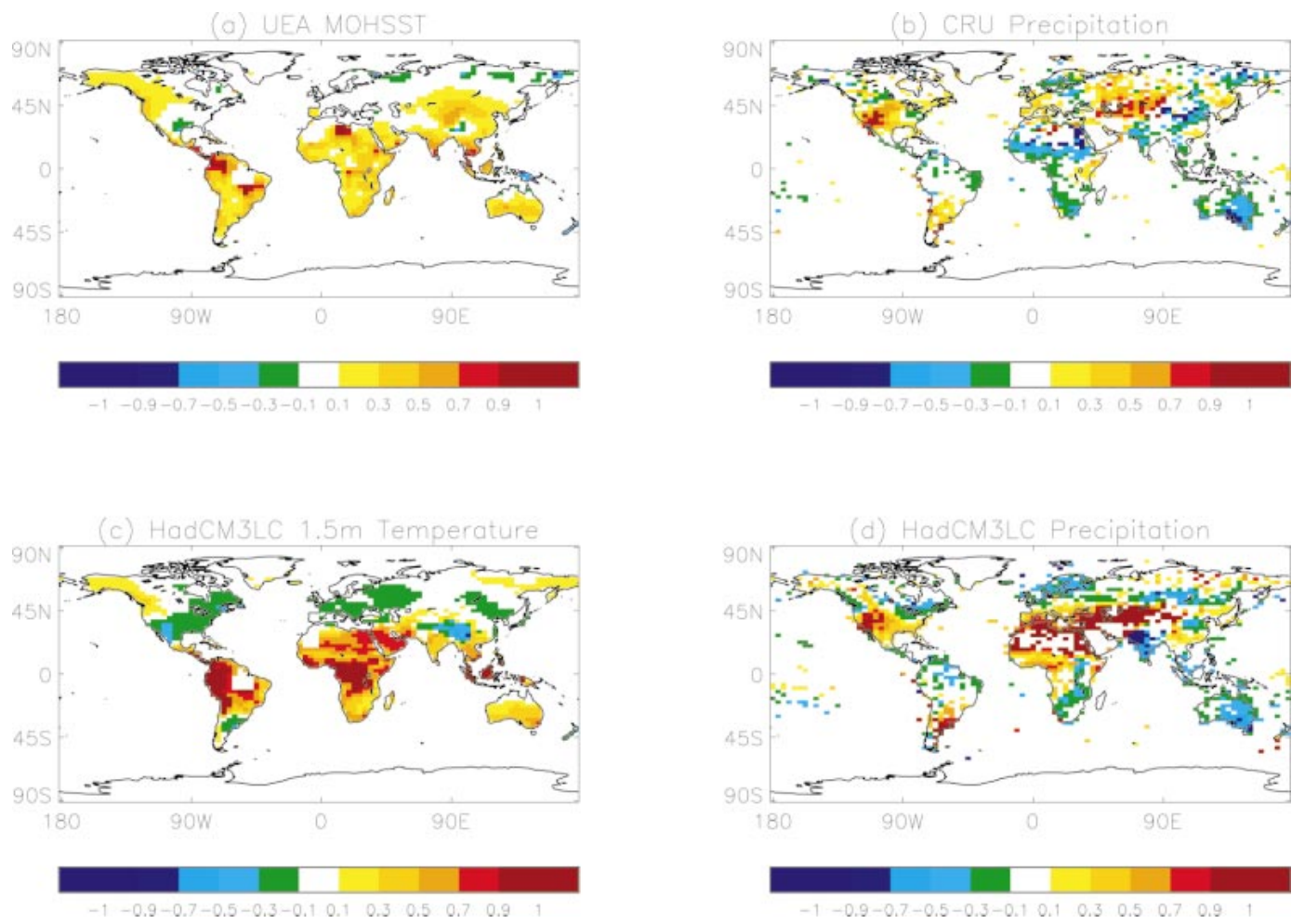

FIG. 6. Regression coefficients of (a) UEA-MOHSST temperature observations, (b) CRU precipitation observations onto observed Niño-3 index, (c) HadCM3LC temperature, and (d) precipitation onto HadCM3LC Niño-3 index.

in the Niño-3 index were $\pm 0.7{ }^{\circ} \mathrm{C}$. In that study, the difference between fluxes in the equatorial Pacific (between $15^{\circ} \mathrm{N}$ and $15^{\circ} \mathrm{S}$ ) during El Niño and La Niña

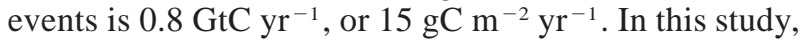
the difference is $20 \mathrm{gC} \mathrm{m}^{-2} \mathrm{yr}^{-1}$. The modeled terrestrial biosphere is about 3.5 times more sensitive than the

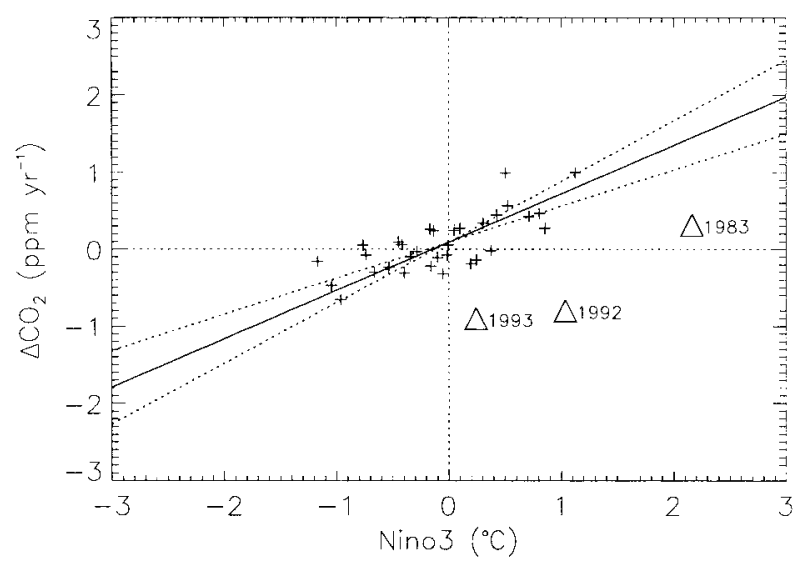

FIG. 7. Observed changes in annual mean $\mathrm{CO}_{2}$ concentration after the anthropogenic influence has been removed (as described in the text) plotted against observed Niño-3 index. Years strongly affected by major volcanic eruptions are denoted by open triangles. The solid line shows a linear regression using data from 1967 to 1981 as described in the text. The dotted lines show the $95 \%$ confidence limits of the regression. ocean. Bousquet et al. (2000) see terrestrial sensitivity double that of the ocean, but this estimate may be low due to unaccounted for volcanic activity during the period of that study. It can be seen in Fig. 9 that the majority of the sensitivity lies in the Tropics. This is the case for both the ocean and terrestrial carbon cycle. This agrees with Le Quere et al. (2000) and Bousquet et al. (2000). Le Quere et al. (2000) also note a region of outgassing during La Niña events in the Southern Ocean near the Drake Passage. ${ }^{1}$ Their value of $0.8 \mathrm{~mol}$ $\mathrm{m}^{-2} \mathrm{yr}^{-1}\left(10 \mathrm{gC} \mathrm{m}^{-2} \mathrm{yr}^{-1}\right)$ is the same size as the patch visible just to the west of the Drake Passage in Fig. 9.

For the ocean there have been some estimates from observations of the change in outgassing of $\mathrm{CO}_{2}$ in the equatorial Pacific associated with ENSO. As can be seen in Fig. 9, the dominant ENSO signal from the modeled ocean occurs in the equatorial Pacific, so any validation of $\mathrm{CO}_{2}$ fluxes in the equatorial Pacific is valuable when considering the global flux. Chavez et al. (1999) estimate the change in the flux of $\mathrm{CO}_{2}$ from the equatorial Pacific Ocean between non-El Niño conditions in 1995/ 96 and El Niño conditions in 1997/98. To compare to the model, a period of the control simulation was chosen with a similar evolution of the Niño-3 index to that found in the 1996-99 period. The comparison of the

\footnotetext{
${ }^{1}$ Waterway connecting Atlantic and Pacific Oceans between South America and Antarctica.
} 

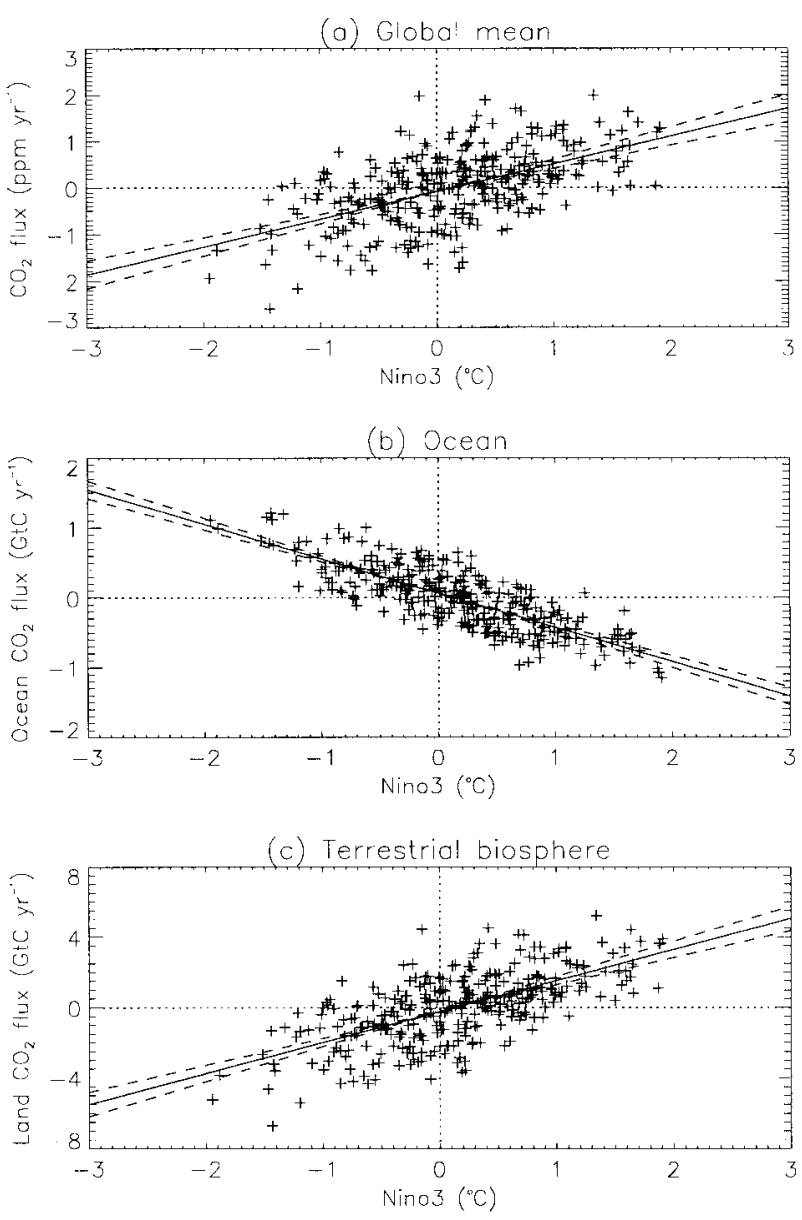

FIG. 8. As in Fig. 7 but for HadCM3LC: (a) global mean $\mathrm{CO}_{2}$ flux to the atmosphere (ppm $\mathrm{yr}^{-1}$ ) for comparison with Fig. 7; (b) ocean

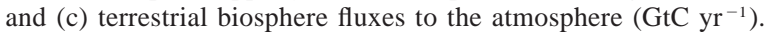

Niño-3 index is shown in Fig. 10a. The change in the flux of $\mathrm{CO}_{2}$ to the atmosphere for this period in the model, moving from non-El Niño conditions to El Niño conditions, is around $0.8 \mathrm{GtC} \mathrm{yr}^{-1}$ (see Fig. 10b), com-

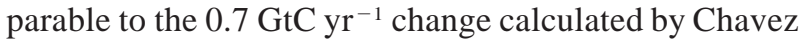
et al. (1999). However the biology in the model shows little reaction. The background level of upwelling on which the ENSO signal is superimposed is too high in the model and levels of nutrient do not generally reach limiting levels. Also more complex biological limitations such as iron limitation are not included. The mechanisms behind the reaction of the modeled ocean to ENSO are investigated in section 5.

\section{2) LocAl ATMOSPHERic $\mathrm{CO}_{2}$ CONCENTRATIONS}

When Bacastow (1976) first noted the correlation between ENSO and atmospheric $\mathrm{CO}_{2}$ changes, it was noted that the correlation was lagged by a number of months and that the lag depended on the location of the measuring station. Bacastow (1976) found the lag between the El Niño cycle and the $\mathrm{CO}_{2}$ concentration
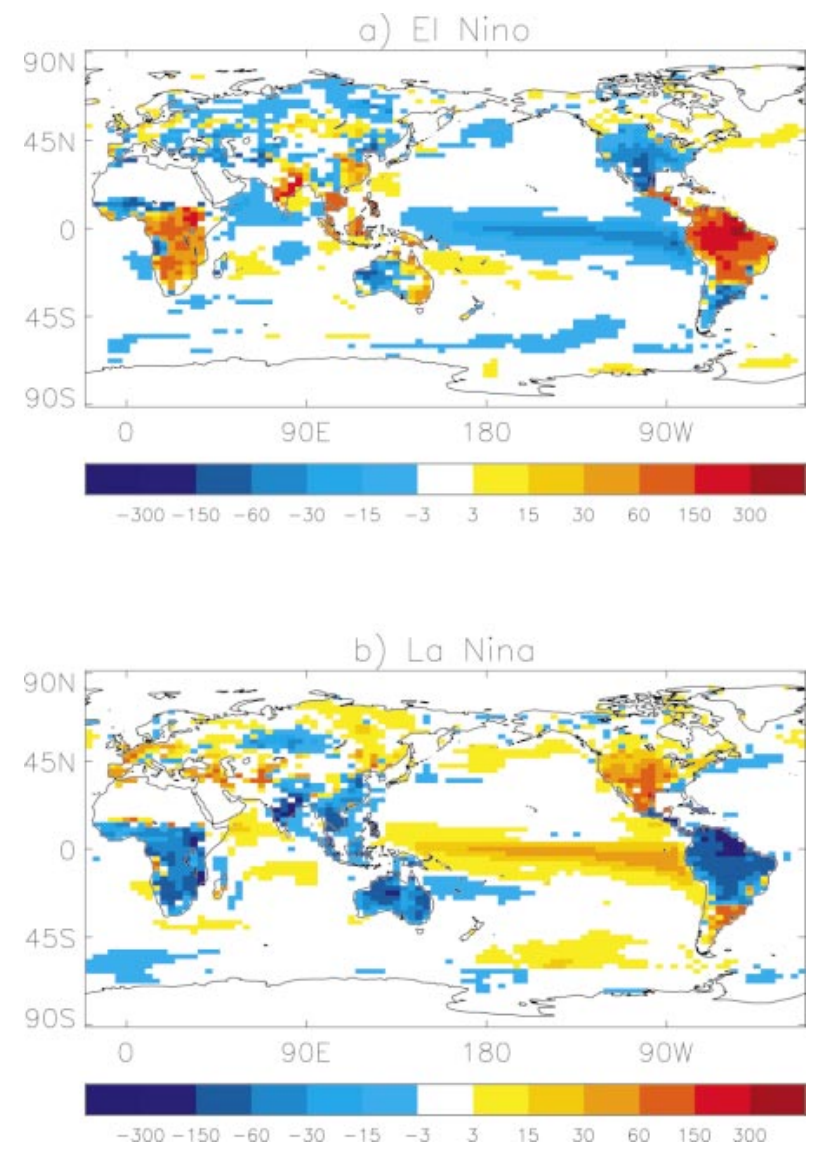

FIG. 9. Distribution of anomalous fluxes $\left(\mathrm{gC} \mathrm{m}^{-2} \mathrm{yr}^{-1}\right)$ for (a) mean El Niño conditions and (b) mean La Niña conditions in HadCM3LC.

changes to be $2 \frac{1}{2}$ months at Mauna Loa and 6 months at the South Pole. Bacastow et al. (1980) also found a lag of 7 months at Ocean Station $\mathrm{P}\left(50^{\circ} \mathrm{N}\right)$.

Monthly $\mathrm{CO}_{2}$ concentration data for three stations, Mauna Loa, South Pole, and Point Barrow, are available from the CDIAC Web site. The correlation of these with Niño-3 index data from the HadISST3 dataset was studied. First the observations were processed as follows:

- A constant fraction (56\%) of anthropogenic emissions was assumed to remain in the atmosphere. This was subtracted from the concentration records to give an anthropogenic-free record.

- A mean seasonal cycle was calculated from the data, and this was used to interpolate any gaps in the data. This was necessary for February, March, and April 1965 for the Mauna Loa data and May 1983 for the South Pole data.

- The mean seasonal cycle was then subtracted from the time series to give the deseasonalized data in much the same way as Elliot et al. (1991). The Niño-3 data are relative to the 1961-90 climatology and so have already been deseasonalized in this manner. 

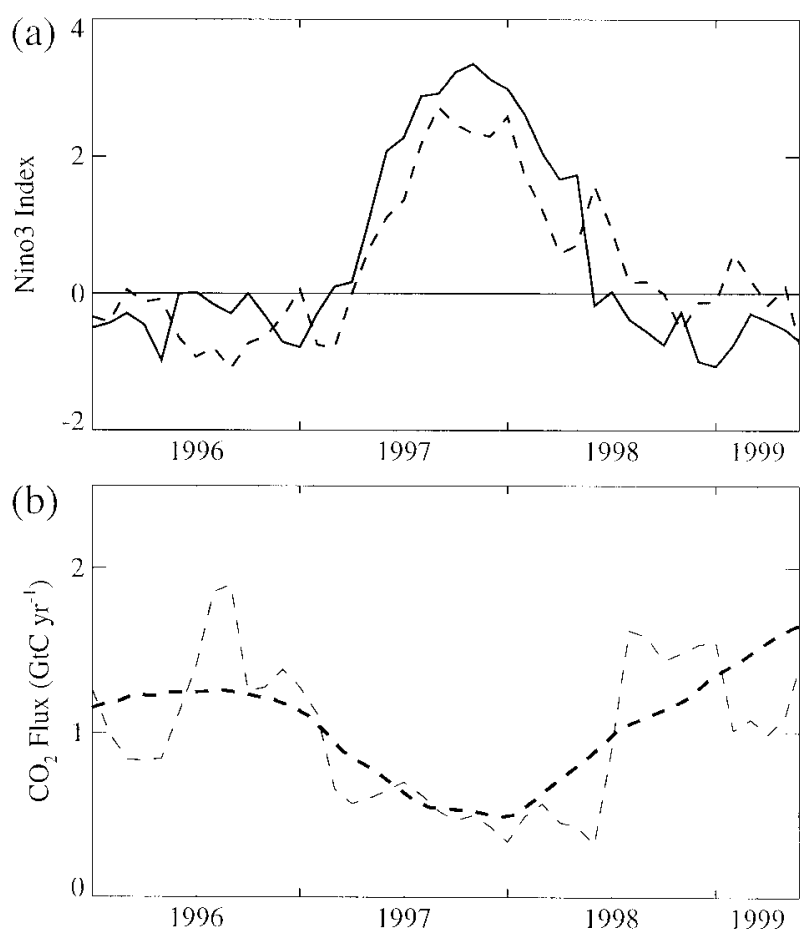

FIG. 10. (a) The Niño-3 index for the period around the 1997/98 El Niño calculated using the HadISST1.1 SST dataset (solid line) Also shown is the Niño-3 index from a portion of the control run exhibiting a similar pattern of Niño-3 index to the 1997/98 observational period (dashed line). (b) The air-sea flux of $\mathrm{CO}_{2}$ for the period of the control run shown by the dashed line in (a) summed over the region $10^{\circ} \mathrm{S}-10^{\circ} \mathrm{N}, 80^{\circ} \mathrm{W}-135^{\circ} \mathrm{E}$. The thin dashed line is monthly data, and the thick dashed line is the 12-month running mean of the monthly data.

- A time series of $\Delta \mathrm{CO}_{2}$ was calculated from the $\mathrm{CO}_{2}$ concentration data.

- The data (both $\Delta \mathrm{CO}_{2}$ and Niño-3) were filtered with a low-pass Chebyshev filter of half-width 10 months to remove frequency components of period 12 months or less.

The resulting time series of monthly $\Delta \mathrm{CO}_{2}$ values were correlated with the Niño-3 data with a varying lag from 0 to 24 months. Although there was a large volcanic eruption (Mount Pinatubo) in 1991 that had a significant effect on global $\mathrm{CO}_{2}$ concentrations (Jones and Cox 2001), it was found here that the correlations

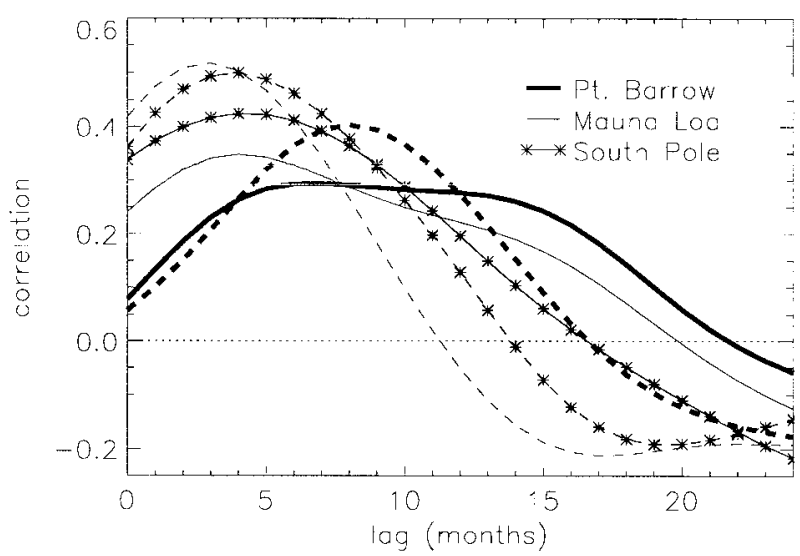

FIG. 11. Variation with lag of the correlation coefficient of the rate of change of atmospheric $\mathrm{CO}_{2}$ with Niño-3 index for three flask measurement stations: Point Barrow (thick dashed line), Mauna Loa (thin dashed line), and the South Pole (starred dashed line). Model results for the three stations are the solid lines-thick, thin, and starred lines, respectively. A positive lag implies that the Niño-3 index leads the $\mathrm{CO}_{2}$ signal.

were not significantly affected by inclusion of post-1991 data, and so the whole data series up to 1998 was used.

Equivalent time series of monthly $\mathrm{CO}_{2}$ concentration data were extracted from the model for the three measurement flask stations and also for Ocean Station P and Fanning Island, and similar deseasonalizations, filtering, and correlations were performed. The results are plotted in Fig. 11, which shows how the correlation coefficient varies with lag for the three stations. Table 1 shows how the magnitude and lag of the maximum correlation varies with observing station for the observations and model data. The values presented in Bacastow et al. (1980) are shown for comparison, although the data used in that study were for a shorter period, and correlations were performed against the Southern Oscillation index rather than Niño-3.

There is good agreement between the lagged correlation behavior in the model and in the observations, in particular between the lags at which the peaks occur. The main difference between the observations and the model is how the correlation drops off with increasing lag as shown in Fig. 11. The model has a tendency to remain more highly correlated for longer lags. The least good fit of the three stations shown in Fig. 11 is for

TABLE 1. Correlation coefficients and lags between atmospheric $\mathrm{CO}_{2}$ concentration at various flask measurement stations and the Niño-3 index. "Obs" are observed values from CDIAC Web site, "model" is results from HadCM3LC, and "Bacastow" represents data presented by Bacastow et al. (1980).

\begin{tabular}{|c|c|c|c|c|c|c|c|}
\hline \multirow[b]{2}{*}{ Station } & \multirow[b]{2}{*}{ Latitude } & \multicolumn{3}{|c|}{ Correlation coefficient } & \multicolumn{3}{|c|}{ Lag (months) } \\
\hline & & Obs & Model & Bacastow & Obs & Model & Bacastow \\
\hline Point Barrow & $71^{\circ} \mathrm{N}$ & 0.40 & 0.29 & & 8 & $6-8$ & \\
\hline Ocean Station P & $50^{\circ} \mathrm{N}$ & & 0.37 & 0.66 & & $6-7$ & 7 \\
\hline Mauna Loa & $19^{\circ} \mathrm{N}$ & 0.52 & 0.35 & 0.52 & 3 & 4 & 3 \\
\hline Fanning Island & $4^{\circ} \mathrm{N}$ & & 0.50 & 0.80 & & 4 & 1 \\
\hline South Pole & $90^{\circ} \mathrm{S}$ & 0.50 & 0.42 & 0.69 & 4 & $4-5$ & 6 \\
\hline
\end{tabular}


Mauna Loa. One possible reason for this is that there is no land in the model at that point; the lack of any contribution to local $\mathrm{CO}_{2}$ concentrations from the terrestrial biosphere may alter the magnitude and timing of the correlations. There is also general agreement with the results of Bacastow et al. (1980), although in that study the peak correlations tended to be higher and occur at shorter lags. Given the similarity between the model and observations when the same data processing is performed, it is possible that this difference is due to the use of slightly different data series and processing techniques.

There are two possible mechanisms that could cause these lags. The rate of change of $\mathrm{CO}_{2}$ at a point will have two components: one due to local fluxes and one due to advection. The lag could be in either or both of these components. For example, at Point Barrow the lag could be due to a delay in the response of the local climatic conditions to the ENSO cycle forcing, or due to a delay in the advection of atmospheric $\mathrm{CO}_{2}$ from the Tropics. The sign of $\mathrm{CO}_{2}$ response at Point Barrow makes it likely that the dominant cause is due to the delay of $\mathrm{CO}_{2}$ advected from the Tropics. This is because the response at Point Barrow is a net increase of $\mathrm{CO}_{2}$ during El Niño events. However, as shown in Fig. 9, the local fluxes in Alaska would cause a net decrease in $\mathrm{CO}_{2}$ if they alone were responsible for the signal. Therefore, the increase seen at Point Barrow is likely to come from the large tropical terrestrial sources. Similarly at the South Pole, there are no major local sources or sinks of $\mathrm{CO}_{2}$ and so any signal seen here must have been advected from elsewhere. Again, the sign of the response indicates that the tropical terrestrial source may be responsible.

In conclusion, we can say that the model accurately represents both the ENSO cycle, and the climate's response to it, and so we are justified in examining the model's carbon cycle response to ENSO. The global mean $\mathrm{CO}_{2}$ response is in close agreement to the observed sensitivity to ENSO forcing. Ocean and land carbon fluxes respond in opposite sense to the forcing with the land becoming a net source and the ocean a net sink during El Niño events. The magnitude of the land response dominates.

On the local scale, the model simulates the response of atmospheric $\mathrm{CO}_{2}$ at different monitoring stations quite well. Both the strength of the correlation with ENSO, and the time lag are well captured.

\section{Response of terrestrial carbon cycle}

Previous studies have forced terrestrial biosphere models using observed climatic anomalies (e.g., Kindermann et al. 1996; Craig 1998; Gerard et al. 1999). These have yielded conflicting conclusions regarding the dominant mechanism for ENSO-driven variability in the carbon cycle. Kindermann et al. (1996) and Gerard et al. (1999) carried out "offline" experiments, which suggested that temperature anomalies were most important. By contrast, Craig (1998) used an atmosphere-land model with prescribed sea surface temperatures to demonstrate the importance of precipitation variability. Here we analyze the online response of the terrestrial biosphere to internally generated ENSO variability in the HadCM3LC coupled climate-carbon cycle model.

The net atmosphere to land $\mathrm{CO}_{2}$ flux, or "Net Ecosystem Productivity (NEP)" is the residual of three large fluxes:

$$
\mathrm{NEP}=\mathrm{GPP}-R_{p}-R_{s} .
$$

Gross Primary Productivity (GPP) is the result of photosynthesis and is dependent on incident photosynthetically active radiation, atmospheric $\mathrm{CO}_{2}$ concentration, soil moisture, leaf temperature, and atmospheric humidity deficit (Cox et al. 1998). About one-half of GPP is returned to the atmosphere by plant respiration $\left(R_{p}\right)$, which is made up of a maintenance component that increases exponentially with temperature and a "growth" component, proportional to the remaining carbon available for growth. The litterfall from vegetation is broken down by microbes, which return $\mathrm{CO}_{2}$ to the atmosphere as the flux from "soil respiration" $\left(R_{s}\right)$. In TRIFFID, soil respiration is assumed to have $q_{10}=2$, which means that this flux doubles for every $10-\mathrm{K}$ warming (all else being equal). There is also a weaker dependence on soil moisture with maximum soil respiration rates at intermediate values of moisture.

Figure 12 shows how the modeled Niño-3 index correlates with NEP and each of these components. During an El Niño event the coupled model produces a net global land to atmosphere $\mathrm{CO}_{2}$ flux, owing largely to negative NEP anomalies in Amazonia, tropical Africa, India, and Australia, which are only partially counteracted by net uptake in the United States and in southernmost South America. The pattern of GPP correlation with Niño-3 shows a resemblance to the modeled correlation between precipitation and Niño-3 (Fig. 6d), suggesting that ENSO-driven GPP changes are as a result of changes in soil water availability. This is especially true in the regions where plants are likely to be water limited, such as India and Australia (strong negative correlations of both GPP and rainfall with Niño-3) and the southwest United States (strong positive correlations of both GPP and rainfall with Niño-3). The correlation between Niño-3 and the plant and soil respiration rates is much more dependent on the temperature changes associated with ENSO. The regions in which annual mean temperature is most tightly tied to ENSO (Amazonia and tropical Africa), are also the regions in which the respiration rates are most highly correlated with Niño-3 (see Figs. 6 and 12).

These correlation maps indicate the extent to which variability in each of the land-atmosphere fluxes is associated with ENSO. It is also useful to look at the magnitude of the response to a given ENSO event. Table 

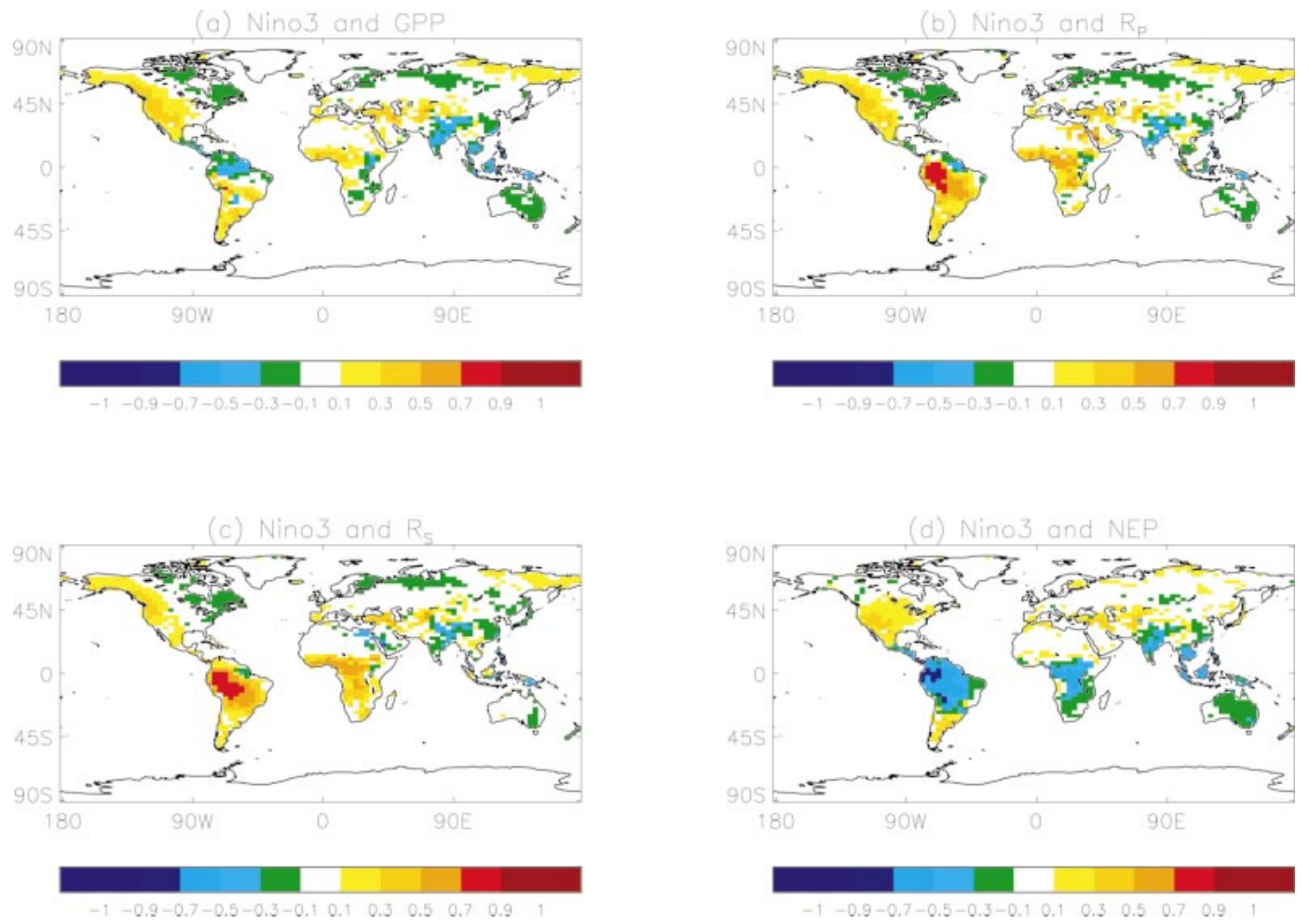

FIG. 12. Correlation of HadCM3LC variables with modeled Niño-3 index: (a) GPP, (b) $\mathrm{R}_{P}$, (c) $\mathrm{R}_{S}$, and (d) NEP.

2 lists the sensitivity of temperature, precipitation, GPP, plant respiration, soil respiration, and NEP for six regions of the world that show significant NEP correlations with Niño-3 (see Table 3). Note that the sign convention used in the model is such that GPP and NEP are positive for flux from the atmosphere and respiration rates are positive for flux to the atmosphere. However Table 2 lists values for $-R_{p}$ and $-R_{s}$ so that all fluxes in the table are positive for flux from the atmosphere to the biosphere. The response of NEP in each region is described in more detail below.

The largest sensitivity of NEP to ENSO is seen in northern Amazonia, where El Niño is associated with a warmer and dryer climate (see Table 2). The negative NEP anomaly is the result of both a reduction in GPP, as well as increases in soil and plant respiration. The reduction in precipitation will tend to reduce GPP through reduced soil water availability. Climatological temperatures in the Tropics are almost optimal for photosynthesis, so the warming may also suppress productivity. Soil respiration responds primarily to temperature, and therefore increases during El Niño. The same is true for the maintenance component of plant respiration, but this increase is balanced by reductions in the growth component (which is proportional to GPP), yielding a much smaller increase in total plant respiration. The result is a large net land to atmosphere $\mathrm{CO}_{2}$ flux during El Niño, primarily as a result of reduced GPP and increased soil respiration.

The response mechanisms are different in other outgassing regions. The dominant climatological change in tropical Asia and Australia is a reduction in rainfall

TABLE 2. Modeled sensitivity to ENSO by region, for annual mean values of $1.5-\mathrm{m}$ air temperature $(T)$, precipitation $(P)$, GPP, plant respiration $\left(R_{P}\right)$, soil respiration $\left(R_{S}\right)$, and NEP. The magnitude of each response has been scaled by the Niño-3 index in kelvin. All values are positive for fluxes from the atmosphere to the biosphere.

\begin{tabular}{lrrrrrrr}
\hline \hline & \multicolumn{2}{c}{ Climate } & & \multicolumn{3}{c}{ Terrestrial carbon cycle $\left(\mathrm{gC} \mathrm{m}^{-2} \mathrm{yr}^{-1} \mathrm{~K}^{-1}\right)$} \\
\cline { 2 - 3 } \cline { 5 - 7 } & $T\left(\mathrm{~K} \mathrm{~K}^{-1}\right)$ & $P\left(\mathrm{~mm} \mathrm{day}^{-1} \mathrm{~K}^{-1}\right)$ & & $\mathrm{GPP}$ & $-R_{p}$ & $-R_{s}$ & NEP \\
\hline Northern Amazonia & 0.48 & -0.10 & & -35 & -12 & -31 & -77 \\
Southern South America & -0.03 & 0.05 & & 55 & -19 & -8 & 29 \\
Tropical Africa & 0.28 & 0.03 & & -1 & -11 & -20 & -32 \\
Tropical Asia & 0.06 & -0.33 & & -60 & 15 & 10 & -35 \\
Australia & 0.07 & -0.23 & & -44 & 9 & -32 & -32 \\
Southern United States & -0.05 & 0.07 & & 40 & -11 & -5 & -5 \\
Global & 0.13 & 0.01 & & -4 & -3 & -5 & -12 \\
\hline
\end{tabular}


TABLE 3. Coordinates used to define the regions described in the text and used in Table 2 .

\begin{tabular}{lcccc}
\hline \hline & West & South & East & North \\
\hline Northern Amazonia & $90^{\circ} \mathrm{W}$ & $25^{\circ} \mathrm{S}$ & $30^{\circ} \mathrm{W}$ & $15^{\circ} \mathrm{N}$ \\
Southern South America & $80^{\circ} \mathrm{W}$ & $60^{\circ} \mathrm{S}$ & $40^{\circ} \mathrm{W}$ & $30^{\circ} \mathrm{S}$ \\
Tropical Africa & $20^{\circ} \mathrm{W}$ & $20^{\circ} \mathrm{S}$ & $60^{\circ} \mathrm{E}$ & $10^{\circ} \mathrm{N}$ \\
Tropical Asia & $70^{\circ} \mathrm{E}$ & $10^{\circ} \mathrm{S}$ & $150^{\circ} \mathrm{E}$ & $35^{\circ} \mathrm{N}$ \\
Australia & $110^{\circ} \mathrm{E}$ & $40^{\circ} \mathrm{S}$ & $160^{\circ} \mathrm{E}$ & $10^{\circ} \mathrm{S}$ \\
Southern United States & $130^{\circ} \mathrm{W}$ & $20^{\circ} \mathrm{N}$ & $70^{\circ} \mathrm{W}$ & $50^{\circ} \mathrm{N}$ \\
\hline
\end{tabular}

under El Niño, which acts to reduce GPP in these waterlimited areas. In both regions there are slight decreases in soil and plant respiration despite small increases in annual mean temperature. The reduction in total plant respiration can be attributed to a decrease in the growth component, which dominates any increase in maintenance respiration. The small decrease in soil respiration is probably due to its dependence on soil moisture, which implies reducing respiration as the soil dries in semiarid regions.

The ecosystems of tropical Africa are also a significant $\mathrm{CO}_{2}$ source during $\mathrm{El} \mathrm{Niño}$, but here yet another balance of flux anomalies is seen. Whereas the outgassing from Australia and tropical Asia is the result of reduced GPP, increased soil and plant respiration is the dominant response in tropical Africa. A negligible change in annual mean precipitation under El Niño yields a negligible change in GPP. The warming (of 0.28 $\mathrm{K}$ in the annual mean) enhances both soil and plant maintenance respiration.

The largest $\mathrm{CO}_{2}$ sinks during El Niño are in the southern parts of North and South America. Both areas experience a slightly wetter and cooler climate, which yields large increases in GPP. There are counteracting increases in plant respiration (due to increases in the growth component), and soil respiration (probably due to the moister soils). In these regions the mechanisms appear to be similar to those in Australia and tropical Asia, but the El Niño perturbations have the opposite sign.

Globally the land is a $\mathrm{CO}_{2}$ source during an El Niño, with GPP decreasing and soil and plant respiration both increasing. The resulting sensitivity of global mean NEP is equivalent to a global carbon anomaly of $1.76 \mathrm{GtC}$ $\mathrm{yr}^{-1}$ per degree of Niño-3 anomaly.

\section{Response of ocean carbon cycle}

It is clear from Fig. 9 showing the distribution of anomalous fluxes of $\mathrm{CO}_{2}$ to the atmosphere for El Niño and La Niña conditions that the dominant signal from the ocean occurs in the equatorial Pacific.

By averaging over the 10 strongest El Niño and the 10 strongest La Niña events for a 100-yr section of the control run, the equatorial Pacific Ocean state can be compared for El Niño conditions, La Niña conditions, and for mean conditions. This analysis is performed for a region in the equatorial Pacific covering the dominant anomalous fluxes shown in Fig. 9. Under El Niño conditions the outgassing of $\mathrm{CO}_{2}$ is suppressed, as compared with an enhancement of outgassing of $\mathrm{CO}_{2}$ under La Niña conditions. This is illustrated by the mean airsea flux of $\mathrm{CO}_{2}$ in the first column of Fig. 13a. For the strong El Niño years the air-sea flux of $\mathrm{CO}_{2}$ is reduced by one-third in comparison with the mean, whereas for the strong La Niña years, the air-sea flux of $\mathrm{CO}_{2}$ is increased by one-third.

To determine the driving process behind ENSO variability in the air-sea flux of $\mathrm{CO}_{2}$, the formula for calculating the air-sea flux is considered. The air-sea flux of $\mathrm{CO}_{2}$ (denoted $F$ ) is the product of three quantities, the solubility of $\mathrm{CO}_{2}\left(K_{0}\right)$, the piston velocity $(v)$, which has a strong dependency on wind speed, and the difference in partial pressure of $\mathrm{CO}_{2}$ between the atmosphere and ocean $\left(\Delta \mathrm{pCO}_{2}\right)$, that is,

$$
F=K_{0} v \Delta \mathrm{pCO}_{2} \text {. }
$$

It is found that the fluctuations in $\Delta \mathrm{pCO}_{2}, K_{0}$ and $v$ over periods less than a month are unimportant in the model at longer timescales, and that the monthly mean air-sea flux of $\mathrm{CO}_{2}$ can be reconstructed from monthly mean values for $\Delta \mathrm{pCO}_{2}, K_{0}$ and $v$. Hence monthly mean data are considered in the following analysis.

To examine the differences between El Niño, La Niña, and mean conditions, monthly climatologies of $\Delta \mathrm{pCO}_{2}$, $K_{0}$, and $v$ were constructed for the strong El Niño years, the strong La Niña years, and the entire control period. These climatologies were used to reconstruct the spatial fields of air-sea flux of $\mathrm{CO}_{2}$. The resulting reconstructed fields were found to be very close to the spatial climatologies of air-sea flux of $\mathrm{CO}_{2}$ for the given periods, which is illustrated by comparing the spatial and temporal mean of the reconstructed air-sea flux fields (column 2 in Fig. 13a) with the mean climatological airsea flux (column 1 in Fig. 13a).

Because using climatological fields of $\Delta \mathrm{pCO}_{2}, K_{0}$, and $v$ in Eq. (2) can reproduce the air-sea $\mathrm{CO}_{2}$ flux so well for El Niño conditions, La Niña conditions, and the entire period, sensitivity experiments can be performed using the climatological fields in Eq. (2) to investigate which process dominates the ENSO variability for the air-sea flux of $\mathrm{CO}_{2}$. To test which quantities cause the air-sea flux of $\mathrm{CO}_{2}$ to differ from the mean under El Niño and La Niña conditions, the air-sea flux of $\mathrm{CO}_{2}$ is reconstructed for El Niño and La Niña conditions, but with either the solubility, the piston velocity, or the $\Delta \mathrm{pCO}_{2}$ fields reverting to the climatology for the entire control period. Results from these sensitivity tests are shown in the final three columns of Fig. 13a. By comparing the mean air-sea flux of $\mathrm{CO}_{2}$ for the sensitivity experiment with the reconstructed value in column 2 of Fig. 13a, and examining whether any deviation is toward or away from the mean value, the dominant sensitivity of the air-sea flux of $\mathrm{CO}_{2}$ can be determined.

The sensitivity of the air-sea flux to the solubility 


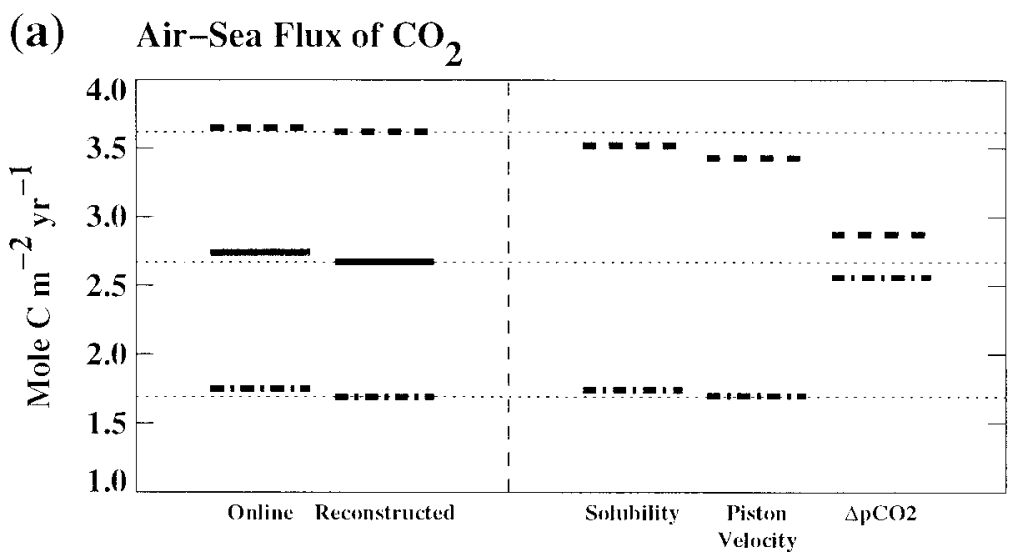

(b) Ocean $\mathrm{pCO}_{2}$

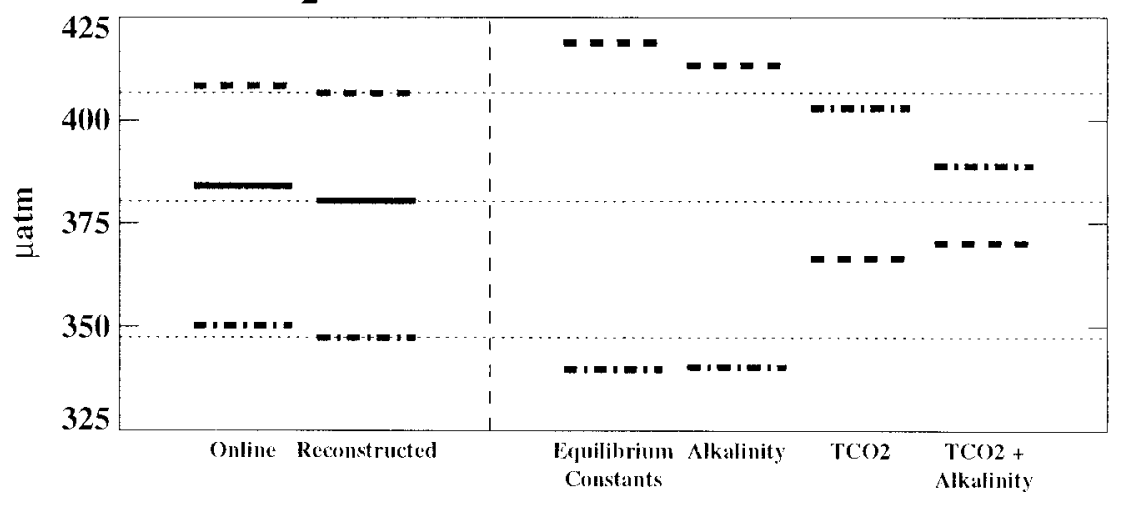

FIG. 13. (a) The mean air-sea flux of $\mathrm{CO}_{2}$ in the equatorial Pacific averaged over $100 \mathrm{yr}$ of the control run (solid lines), the 10 strongest El Niños (dash-dotted lines), and the 10 strongest La Niñas (dashed lines). "Online" is from the model run, "Reconstructed" is calculated offline from model climatologies of solubility, piston velocity, and $\Delta \mathrm{pCO}_{2}$. The final three columns are sensitivity tests (see text for details). (b) As in (a) but for ocean $\mathrm{pCO}_{2}$. This is reconstructed from model climatological fields of the equilibrium constants, dissolved inorganic carbon $\left(\mathrm{tCO}_{2}\right)$, and alkalinity as described in the text.

and piston velocity is found to be small when compared with the sensitivity to the $\Delta \mathrm{pCO}_{2}$. Under El Niño or La Niña conditions, if the $\Delta \mathrm{pCO}_{2}$ is replaced by the mean climatological field, the air-sea flux of $\mathrm{CO}_{2}$ reverts $80 \%$ of the way back toward the mean climatology. This is saying that under El Niño conditions, the majority of the reduction in outgassing is due to a reduction in the $\Delta \mathrm{pCO}_{2}$. There is a smaller contribution to the reduction of outgassing from reduced winds reducing the piston velocity and from lower solubility due to warmer sea surface temperatures. There is a similar argument for the increase in outgassing under La Niña conditions.

In the equatorial Pacific region, the atmospheric $\mathrm{pCO}_{2}$ varies little at the interannual timescale (order $5 \mathrm{ppm}$ ) when compared with the variability in the ocean $\mathrm{pCO}_{2}$ (order $100 \mathrm{ppm}$ ). Hence the ENSO variability in outgassing in the equatorial Pacific is driven by changes in $\Delta \mathrm{pCO}_{2}$ that are dominated by changes in the ocean $\mathrm{pCO}_{2}$. In order to determine the driving process behind the ENSO variability in ocean $\mathrm{pCO}_{2}$, a similar analysis to that described above is performed for the ocean $\mathrm{pCO}_{2}$.

The ocean $\mathrm{pCO}_{2}$ depends on the following: the concentration of dissolved inorganic carbon (known as $\mathrm{tCO}_{2}$ or DIC); the partitioning of $\mathrm{tCO}_{2}$ between chemical species; and the alkalinity. Climatologies for $\mathrm{tCO}_{2}$, alkalinity, and the equilibrium constants determining the chemical partitioning of $\mathrm{tCO}_{2}$ (which are dependent on temperature and salinity) are calculated for El Niño, La Niña, and mean conditions. As with the air-sea flux of $\mathrm{CO}_{2}$, the ocean $\mathrm{pCO}_{2}$ can be reconstructed from the climatologies (see columns 1 and 2 of Fig. 13b) and similar sensitivity experiments can be performed.

The sensitivity experiments show that the greatest sensitivity of the ocean $\mathrm{pCO}_{2}$ is to the surface $\mathrm{tCO}_{2}$ concentration (see the final four columns in Fig. 13b). For example, under El Niño conditions, if the $\mathrm{tCO}_{2}$ field is replaced by the mean climatology, the mean $\mathrm{pCO}_{2}$ increases from 347.4 to $402.9 \mu \mathrm{atm}$. In fact the other factors influencing the ocean $\mathrm{pCO}_{2}$, that is, the equilib- 
rium constants and the alkalinity, act in the opposite sense to the $\mathrm{tCO}_{2}$, offsetting some of the effect of changes in $\mathrm{tCO}_{2}$. For example, under El Niño conditions, the reduced surface $\mathrm{tCO}_{2}$ concentration would reduce outgassing even further than observed in the model, were it not for compensating changes in alkalinity and the equilibrium constants.

With the ocean $\mathrm{pCO}_{2}$, and hence outgassing, found to be most dependent on the $\mathrm{tCO}_{2}$ concentration, there remains the question as to what drives the ENSO variability in equatorial Pacific $\mathrm{tCO}_{2}$. Nutrient in the surface equatorial Pacific is supplied by strong upwelling and is consumed by phytoplankton growth. The modeled interannual variability of phytoplankton growth is minimal in the equatorial Pacific, with a maximum influence on nutrient of $1 \mathrm{mmol} \mathrm{N} \mathrm{m}^{-3}$. The interannual variability in nutrient is of greater magnitude than this, as it is dominated by variability in upwelling. There is a strong correlation between the variability in nutrient and the variability in $\mathrm{tCO}_{2}$ (correlation coefficient of 0.97). This shows that in the model, it is the ENSO variability in upwelling that controls the surface $\mathrm{tCO}_{2}$ concentration.

It can be concluded that in the model it is variability in the upwelling of carbon-rich deep water in the equatorial Pacific that is the major cause of the ENSO-induced variability in the air-sea flux of $\mathrm{CO}_{2}$. This agrees with the findings of previous studies (e.g., Winguth et al. 1994; Feely 1987). However, as has been shown in the sensitivity experiments, the magnitude of the variability in the air-sea flux is reduced by the upwelled waters being higher in alkalinity and also by the effect of temperature and salinity on the chemical partitioning of $\mathrm{tCO}_{2}$. The magnitude of the variability of the airsea flux is enhanced by the effect of temperature on the solubility of $\mathrm{CO}_{2}$ and also by the ENSO variability in the wind speed.

\section{Conclusions}

When a constant fraction of the anthropogenic carbon emissions to the atmosphere is subtracted from the interannual changes in atmospheric $\mathrm{CO}_{2}$ concentration, significant interannual variability remains. In the absence of any volcanic forcing, most of this remaining variability can be explained by the natural carbon cycle's response to the El Niño-Southern Oscillation (ENSO) cycle. This response of the natural carbon cycle provides a valuable means of validating carbon cycle models.

We have used a GCM with an interactive carbon cycle to model the response of the natural carbon cycle to ENSO forcing. The model's ENSO cycle and its related climatic response are realistic, and the model's carbon cycle response to this forcing agrees with observations. The response of the terrestrial biosphere and the ocean carbon cycle are in opposite senses, with the land becoming a net source and the ocean a net sink of $\mathrm{CO}_{2}$ during El Niño events. This behavior also agrees with observations. The model has been used to study in more detail the mechanisms involved.

It is the ENSO-induced variability in upwelling of carbon-rich deep water that is the dominant cause of the ocean becoming a net sink of $\mathrm{CO}_{2}$ during an El Niño event. During an El Niño event, the upwelling in the equatorial Pacific is much reduced, thus reducing the amount of cold, carbon-rich deep water reaching the surface. This results not just in the familiar El Niño SST warming pattern, but also in a reduction of surface $\mathrm{pCO}_{2}$ in that region, and hence a reduction in the normally large outgassing of $\mathrm{CO}_{2}$ to the atmosphere. The reduced winds in this region also play a role in reducing the airsea flux. The reduced solubility of $\mathrm{CO}_{2}$ in the warmer waters acts to increase the outgassing slightly, but this effect is small when compared with the reduced $\Delta \mathrm{pCO}_{2}$. The opposite occurs during La Niña events; increased upwelling leads to elevated surface $\mathrm{pCO}_{2}$ values and hence enhanced outgassing. This results in the ocean becoming a net source during La Niña years.

There are limitations in the model in representing all the important oceanic processes for the carbon cycle in the equatorial Pacific. At the present coarse ocean resolution, the complex current system in the equatorial Pacific is not sufficiently resolved. For the ocean biology, the reaction to ENSO is minimal, likely due to excessive equatorial upwelling of nitrate in the model and structural limitations of the ecosystem model; for example, iron limitation of phytoplankton growth is not included. However the response of the flux of carbon to the atmosphere related to the ENSO variability is generally captured by the ocean model.

The terrestrial biosphere becomes a net source of $\mathrm{CO}_{2}$ to the atmosphere during El Niño events. This response is mainly tropical in origin, where GPP is reduced by the warmer temperatures and decreased precipitation caused by the El Niño, and respiration rates are increased by the warmer temperatures. These effects combine to produce a negative NEP anomaly, and thus the tropical biosphere becomes a significant source of $\mathrm{CO}_{2}$. Other parts of the world have varying responses to ENSO, either through different responses of local vegetation to climatic forcing, or through the different response of local climate to the ENSO forcing. Again, the opposite happens in La Niña years; generally decreased temperatures lead to increased GPP and decreased respiration and hence a net uptake by the biosphere.

Overall the land response is of a larger magnitude than the ocean response and so the net response of the global carbon cycle to ENSO forcing is that atmospheric $\mathrm{CO}_{2}$ increases during El Niño events and decreases during La Niña events.

Understanding the natural carbon cycle's response to climate anomalies such as ENSO will help to reduce uncertainties in predictions of its response to anthropogenic climate change, such as those presented by Cox et al. (2000). This is especially true if, as was described earlier, the pattern of climate change in the next century 
is "El Niño-like" (Roeckner et al. 1999; Meehl et al. 2000; Boer et al. 2000). A realistic response to internal climate variability is also important if a carbon cycle model is to be coupled to a GCM for climate change predictions. The model, HadCM3LC, is able to capture the behavior of the individual components of the carbon cycle due to ENSO forcing, and it recreates the global mean response accurately.

Acknowledgments. This work was supported by the UK DETR Climate Prediction Programme under Contract PECD 7/12/37. We are grateful to our colleagues: Richard Betts, Richard Essery, and Ian Totterdell (Southampton Oceanography Centre) who were all involved in the development of the coupled climate-carbon cycle GCM, and to David Sexton for help with statistical packages for analyzing the data. We used data from the following valuable sources: I. G. Enting, T. M. L. Wigley, and M. Heimann: Dataset DB1009; C. D. Keeling and T. P. Whorf: Dataset NDP001; G. Marland, T. Boden, R. J. Andres, and C. Johnston: Dataset NDP030.

\section{REFERENCES}

Archer, D., T. Takahashi, S. Sutherland, J. Goddard, D. Chipman, K. Rodgers, and H. Ogura, 1996: Daily, seasonal and interannual variability of sea-surface carbon and nutrient concentration in the equatorial Pacific Ocean. Deep-Sea Res., 43, 779-808.

Bacastow, R., 1976: Modulation of atmospheric carbon dioxide by the Southern Oscillation. Nature, 261, 116-118.

_ J. Adams, C. Keeling, D. Moss, T. Whorf, and C. Wong, 1980: Atmospheric carbon dioxide, the southern oscillation, and the weak 1975 El Niño. Science, 210, 66-68.

Boer, G. J., G. Flato, and D. Ramsden, 2000: A transient climate change simulation with greenhouse gases and aerosol forcing: Projected climate to the twenty-first century. Climate Dyn., 16, 427-450.

Bousquet, P., P. Peylin, P. Ciais, C. Le Quere, P. Friedlingstein, and P. Tans, 2000: Regional changes in $\mathrm{CO}_{2}$ fluxes of land and ocean since 1980. Science, 290, 1342-1346.

Chatfield, C., 1984: The Analysis of Time Series. 3d ed. Chapman and Hall, $241 \mathrm{pp}$.

Chavez, F. P., P. G. Strutton, G. E. Friedrich, R. A. Feely, G. C Feldman, D. G. Foley, and M. J. McPhaden, 1999: Biological and chemical response of the Equatorial Pacific Ocean to the 1997-98 El Niño. Science, 286, 2126-2131.

Ciais, P., and Coauthors, 1995: Partitioning of ocean and land uptake of $\mathrm{CO}_{2}$ as inferred by delta-13C measurements from NOAA CMDL global air sampling network. J. Geophys. Res., 100, 5051-5070.

Cleveland, W., A. Freeny, and T. Graedel, 1983: The seasonal component of atmospheric $\mathrm{CO}_{2}$ : Information from new approaches to the decomposition of seasonal time series. J. Geophys. Res., 88, 10 934-10 946.

Collatz, G. J., J. T. Ball, C. Grivet, and J. A. Berry, 1991: Physiological and environmental regulation of stomatal conductance, photosynthesis and transpiration: A model that includes a laminar boundary layer. Agric. and Forest Meteor., 54, 107-136.

_, M. Ribas-Carbo, and J. A. Berry, 1992: A coupled photosynthesis-stomatal conductance model for leaves of $\mathrm{C}_{4}$ plants. Aus. J. Plant Physiol., 19, 519-538.

Collins, M., 2000: The El Niño-Southern Oscillation in the second Hadley Centre coupled model and its response to greenhouse warming. J. Climate, 13, 1299-1312.
S. F. B. Tett, and C. Cooper, 2001: The internal climate variability of HadCM3, a version of the Hadley Centre coupled model without flux adjustments. Climate Dyn., 61-81.

Cox, P. M., 2001: Description of the TRIFFID dynamic global vegetation model. Hadley Centre, Met Office Tech. Note 24, 16 pp.

- C. Huntingford, and R. J. Harding, 1998: A canopy conductance and photosynthesis model for use in a GCM land surface scheme. J. Hydrology, 212-213, 79-94.

— , R. A. Betts, C. B. Bunton, R. L. H. Essery, P. R. Rowntree, and J. Smith, 1999: The impact of new land surface physics on the GCM simulation of climate and climate sensitivity. Climate Dyn., 15, 183-203.

, C. Jones, S. Spall, and I. Totterdell, 2000: Acceleration of global warming due to carbon-cycle feedbacks in a coupled climate model. Nature, 408, 184-187.

_ _ C. D. Jones, S. A. Spall, and I. J. Totterdell, 2001: Modelling vegetation and the carbon cycle as interactive elements of the climate system. Proc. Roy. Meteor. Soc. Millennium Conf., Cambridge, United Kingdom, Royal Meteorological Society, in press.

Craig, S., 1998: The response of terrestrial carbon exchange and atmospheric $\mathrm{CO}_{2}$ concentrations to El Niño SST forcing. Stockholm University Rep. CM-94, 39 pp.

Cramer, W., and Coauthors, 2001: Global response of terrestrial ecosystem structure and function to $\mathrm{CO}_{2}$ and climate change: Results from six dynamic global vegetation models. Global Change Biol., 7, 357-374.

Elliot, W., J. Angell, and K. Thoning, 1991: Relation of atmospheric $\mathrm{CO}_{2}$ to tropospheric sea and air temperatures and precipitation. Tellus, 43B, 144-155.

Enting, I., 1987: On the use of smoothing splines to filter $\mathrm{CO}_{2}$ data. J. Geophys. Res., 92, $10977-10984$

Feely, R., 1987: Distribution of chemical tracers in the eastern equatorial Pacific during and after the 1982-1983 El Niño/Southern Oscillation event. J. Geophys. Res., 92, 6545-6558.

Francey, R., P. Tans, C. Allison, I. Enting, J. White, and M. Trollier, 1995: Changes in oceanic and terrestrial carbon uptake since 1982. Nature, 373, 326-330.

Gammon, R., E. Sundquist, and P. Frasier, 1985: History of carbon dioxide in the atmosphere. Atmospheric Carbon Dioxide and the Global Carbon Cycle. U.S. Department of Energy (Rep. DOE/ ER-0239), 25-62.

Gerard, J., B. Nemry, L. Francois, and P. Warnant, 1999: The interannual change of atmospheric $\mathrm{CO}_{2}$ : Contribution of subtropical ecosystems? Geophys. Res. Lett., 26, 243-246.

Gordon, C., C. Cooper, C. A. Senior, H. Banks, J. M. Gregory, T. C. Johns, J. F. B. Mitchell, and R. A. Wood, 2000: The simulation of SST, sea ice extents and ocean heat transports in a version of the Hadley Centre coupled model without flux adjustments. Climate Dyn., 16, 147-168.

Hulme, M., 1994: Validation of large-scale precipitation fields in general circulation models. Global Precipitation and Climate Change, M. Desbois, and F. Desalmand, Eds., NATO, SpringerVerlag, 387-405.

Huntingford, C., P. Cox, and T. Lenton, 2000: Contrasting responses of a simple terrestrial ecosystem model to global change. Ecol. Modell., 134, 41-58.

Jones, C., and P. Cox, 2001: Modelling the volcanic signal in the atmospheric $\mathrm{CO}_{2}$ record. Global Biogeochem. Cycles, 15, 453 465.

Karl, T. R., R. W. Knight, and N. Plummer, 1995: Trends in highfrequency climate variability in the twentieth century. Nature, 377, 217-220.

Keeling, C., R. Bacastow, A. Carter, S. Piper, T. Whorf, M. Heimann, W. Mook, and H. Roeloffzen, 1989: A three-dimensional model of atmospheric $\mathrm{CO}_{2}$ transport based on observed winds: 1. Analysis of observational data. Aspects of Climate Variability in the Pacific and the Western Americas, Geophysical Monogr. Series, No. 55, Amer. Geophys. Union, 165-236.

, T. Whorf, M. Whalen, and J. V. der Plicht, 1995: Interannual 
extremes in the rate of rise of atmospheric carbon dioxide since 1980. Nature, 375, 666-670.

Kindermann, J., G.Wurth, and G. Kohlmaier, 1996: Interannual variation of carbon exchange fluxes in terrestrial ecosystems. Global Biogeochem. Cycles, 10, 737-755.

Knutson, T. R., S. Manabe, and D. Gu, 1997: Simulated ENSO in a global coupled ocean-atmosphere model: Multidecadal amplitude modulation and $\mathrm{CO}_{2}$ sensitivity. J. Climate, 10, 42-63.

Le Quere, C., J. Orr, P. Monfray, O. Aumont, and G. Madec, 2000: Interannual variability of the oceanic sink of $\mathrm{CO}_{2}$ from 1979 through 1997. Global Biogeochem. Cycles, 14, 1247-1265.

Liew, S., O. Lim, L. Kwoh, and H. Lim, 1998: A study of the 1997 forest fires in South East Asia using SPOT Quicklook Mosaics. Proc. International Geoscience and Remote Sensing Symp., Seattle, Washington, IEEE Geoscience and Remote Sensing Society, 879-881.

McGuire, A., J. Melillo, L. Joyce, D. Kicklighter, A. Grace, B. Moore III, and C. Vorosmarty, 1992: Interactions between carbon and nitrogen dynamics in estimating net primary productivity for potential vegetation in North America. Global Biogeochem. Cycles, 6, 101-124.

Meehl, G. A., G. W. Branstator, and W. M. Washington, 1993: Tropical Pacific interannual variability and $\mathrm{CO}_{2}$ climate change. J. Climate, 6, 42-63.

— W. D. Collins, B. Boville, J. T. Kiehl, T. M. L. Wigley, and J. M. Arblaster, 2000: Response of the NCAR Climate System Model to increased $\mathrm{CO}_{2}$ and the role of physical processes. $J$. Climate, 13, 1879-1898.

Myneni, R., S. Los, and C. Tucker, 1996: Satellite-based identification of linked vegetation index and sea surface temperature anomaly areas from 1982-1990 for Africa, Australia and South America. Geophys. Res. Lett., 23, 729-732.

- C. Tucker, G. Asrar, and C. Keeling, 1998: Interannual variations in satellite-sensed vegetation index data from 1981 to 1991. J. Geophys. Res., 103, 6145-6160.

Nakazawa, T., S. Morimoto, S. Aoki, and M. Tanaka, 1997: Temporal and spatial variations of the carbon isotopic ratio of atmospheric carbon dioxide in the west Pacific region. J. Geophys. Res., 102, $1271-1285$.

Nicholls, N., 1991: The El Niño/Southern Oscillation and Australian vegetation. Vegetation and Climate Interactions in Semi-Arid Regions, A. Henderson-Sellers and A. Pitman, Eds., Advances in Vegetation Science, Vol. 12, Kluwer, 23-36.
Orr, J. C., 1996: The ocean carbon-cycle intercomparison project of IGBP/GAIM. Ocean Storage of Carbon Dioxide, Workshop 3: International Links and Concerns, W. Ormerod, Ed., IEA R+D Programme, CRE Group Ltd., 33-52.

Palmer, J. R., and I. J. Totterdell, 2001: Production and export in a global ocean ecosystem model. Deep-Sea Res., 48, 1169-1198.

Parker, D. E., C. K. Folland, and M. Jackson, 1995: Marine surface temperature: Observed variations and data requirements. Climatic Change, 31, 559-600.

Raich, J., and W. Schlesinger, 1992: The global carbon dioxide flux in soil respiration and its relationship to vegetation and climate. Tellus, 44B, 81-99.

Rayner, N. A., D. E. Parker, P. Frich, E. B. Horton, C. K. Folland, and L. V. Alexander, 2000: SST and sea-ice fields for ERA40. Proc. of the Second WCRP Int. Conf. on Reanalyses, Wokefield Park, Reading, United Kingdom, World Climate Research Program, 18-21.

Rayner, P., and R. Law, 1999: The interannual variability of the global carbon cycle. Tellus, 51B, 210-212.

Roeckner, E., L. Bengtsson, J. Feichter, J. Lelieveld, and H. Rodhe, 1999: Transient climate change simulations with a coupled atmosphere-ocean GCM including the tropospheric sulfur cycle. J. Climate, 12, 3004-3032.

Taylor, N., 1995: Seasonal uptake of anthropogenic $\mathrm{CO}_{2}$ in an ocean circulation model. Tellus, 47B, 145-169.

Tett, S. F. B., T. C. Johns, and J. F. B. Mitchell, 1997: Global and regional variability in a coupled AOGCM. Climate Dyn., 13, 303-323.

Timmermann, A., J. Oberhuber, A. Bacher, M. Esch, M. Latif, and E. Roeckner, 1999: Increased El Niño frequency in a climate model forced by future greenhouse warming. Nature, 398, 694696.

Wilson, M. F., and A. Henderson-Sellers, 1985: A global archive of land cover and soils data for use in general circulation climate models. J. Climatol., 5, 119-143.

Winguth, A., M. Heimann, K. Kurz, E. Maier-Reimer, U. Mikolajewicz, and J. Segschneider, 1994: El Niño-Southern Oscilation related fluctuations of the marine carbon cycle. Global Biogeochem. Cycles, 8, 39-63.

Wong, C., Y. Chan, J. Page, G. Smith, and R. Bellegay, 1993: Changes in equatorial $\mathrm{CO}_{2}$ flux and new production estimated from $\mathrm{CO}_{2}$ and nutrient levels in Pacific surface waters during the 1986/87 El Niño. Tellus, 45B, 64-79. 